\title{
ARTICLE
}

Cellular and Molecular Biology

\section{Metabolic reprogramming and Notch activity distinguish between non-small cell lung cancer subtypes}

\author{
Katherine Sellers ${ }^{1,7}$, Thaddeus D. Allen ${ }^{2,3}$, Michael Bousamra II,5, JinLian Tan ${ }^{4,8}$, Andrés Méndez-Lucas ${ }^{1}$, Wei Lin ${ }^{1}$, Nourdine Bah ${ }^{1}$, \\ Yelena Chernyavskaya ${ }^{6}$, James I. MacRae ${ }^{1}$, Richard M. Higashi ${ }^{6}$, Andrew N. Lane ${ }^{6}$, Teresa W.-M. Fan ${ }^{6}$ and Mariia O. Yuneva ${ }^{1}$
}

BACKGROUND: Previous studies suggested that the metabolism is differently reprogrammed in the major subtypes of non-small cell lung cancer (NSCLC), squamous cell carcinomas (SCC) and adenocarcinomas (AdC). However, a comprehensive analysis of this differential metabolic reprogramming is lacking.

METHODS: Publicly available gene expression data from human lung cancer samples and cell lines were analysed. Stable isotope resolved metabolomics were performed on SCC and ADC tumours in human patients and in freshly resected tumour slices.

RESULTS: Analysis of multiple transcriptomics data from human samples identified a SCC-distinguishing enzyme gene signature. SCC tumours from patients infused with $\left[\mathrm{U}^{13}{ }^{13} \mathrm{C}\right]$-glucose and SCC tissue slices incubated with stable isotope tracers demonstrated differential glucose and glutamine catabolism compared to AdCs or non-cancerous lung, confirming increased activity through pathways defined by the SCC metabolic gene signature. Furthermore, the upregulation of Notch target genes was a distinguishing feature of SCCs, which correlated with the metabolic signature. Notch and MYC-driven murine lung tumours recapitulated the SCCdistinguishing metabolic reprogramming. However, the differences between SCCs and AdCs disappear in established cell lines in 2D culture.

CONCLUSIONS: Our data emphasise the importance of studying lung cancer metabolism in vivo. They also highlight potential targets for therapeutic intervention in SCC patients including differentially expressed enzymes that catalyse reactions in glycolysis, glutamine catabolism, serine, nucleotide and glutathione biosynthesis.

British Journal of Cancer (2019) 121:51-64; https://doi.org/10.1038/s41416-019-0464-z

\section{BACKGROUND}

Lung cancer kills more than 1.5 million patients worldwide each year. ${ }^{1}$ Roughly $85 \%$ of all lung malignancies are non-small cell lung cancers (NSCLC), which mostly consist of adenocarcinoma (AdC) and squamous cell carcinoma (SCC) histotypes. ${ }^{2}$ Although there are several targeted lung cancer treatments for AdC including the EGFR TKI inhibitors, inhibitors of abnormal ALK and several antibodies among others, ${ }^{3}$ only a few have recently been approved for SCC, including a monoclonal antibody against EGFR, Necitumumab ${ }^{4}$ and immune checkpoint inhibitors Nivolumab $^{5}$ and Pembrolizumab. ${ }^{6}$

Tumour metabolism is an emerging source of novel targets, as cancers alter their metabolism in order to facilitate proliferation, migration and survival in the tumour microenvironment. ${ }^{7}$ The notion that altered metabolism is a hallmark of tumorigenesis ${ }^{8}$ is underscored by the discovery that driver oncogenes and tumour suppressors modulate enzyme expression and/or post-translational modifications, which leads to specific metabolic changes. ${ }^{9}$ Importantly, these oncogene-driven metabolic changes create cancer cell dependencies that can be exploited therapeutically. ${ }^{10,11}$
We, and others, have shown that human and mouse NSCLC's have a distinct metabolic profile and activity compared with noncancerous (NC) lung tissue. ${ }^{12-15}\left[\mathrm{U}^{-13} \mathrm{C}\right]$-glucose infusion into human NSCLC patients and stable isotope-resolved metabolomic (SIRM) analysis demonstrated that tumours increase oxidation of glucose through glycolysis and the Krebs cycle. ${ }^{13,14}$ However, these studies assessed glucose utilisation in NSCLC tumour tissues without addressing how metabolism in tumours of different histotypes is altered in comparison with normal lung (metabolic reprogramming). Previous metabolomic and proteomic studies of human and murine lung tumours have suggested that AdCs and SCCs differ metabolically, ${ }^{16,17}$ but none robustly defined which metabolic pathways were altered specifically in SCCs.

Therefore, we asked whether the metabolic reprogramming observed in human NSCLC is histology-specific. Transcriptomics revealed a 24-metabolic gene signature, which distinguished SCCs and AdCs and which was consistent with alterations in 5 metabolic pathways as assessed by SIRM in lung cancer patients and tissue slices. While conducting our bioinformatic analysis we discovered that the upregulation of Notch target genes was a

\footnotetext{
${ }^{1}$ The Francis Crick Institute, London, UK; ${ }^{2}$ G.W. Hooper Research Foundation, University of California, San Francisco, CA, USA; ${ }^{3}$ Tradewind BioScience, Inc., Daly City, CA, USA; ${ }^{4}$ James Graham Brown Cancer Center, University of Louisville, Louisville, KY, USA; ${ }^{5}$ Baptist Health Medical Group, Thoracic Surgery, New Albany, IN, USA and ${ }^{6}$ Center for Environmental and Systems Biochemistry, Dept. Toxicology and Cancer Biology, University of Kentucky, Lexington, KY, USA

Correspondence: Teresa W.-M. Fan (teresa.fan@uky.edu) or Mariia O. Yuneva (Mariia.Yuneva@crick.ac.uk)

${ }^{7}$ Present address: Agios Pharmaceuticals, Cambridge, MA, USA

${ }^{8}$ Present address: Dental-Oral Immunity \& Infectious Diseases, Dept. Medicine, University of Louisville, Louisville, KY, USA
}

Received: 26 June 2018 Revised: 1 February 2019 Accepted: 7 March 2019

Published online: 22 May 2019 
52

distinguishing feature of SCCs. To investigate this further, we utilised a murine model of NOTCH1-driven lung cancer. Overexpression of activated NOTCH1 and its downstream target $M Y C$ in mouse lung produced tumours that recapitulated the SCCdistinguishing metabolism. Interestingly, the relationship between histotypes, oncogenic signalling and metabolic gene signature were lost in established cancer cell lines.

Together, this study expands on previous research by defining histotype-specific metabolic reprogramming in NSCLCs and monitoring carbon utilisation from isotopically labelled glucose and glutamine into pathways beyond glycolysis and the Krebs cycle. Moreover, it links metabolic reprogramming to oncogenic signalling by demonstrating a Notch-associated metabolic phenotype in lung SCCs, which could represent novel vulnerabilities for future therapeutic intervention. Finally, it demonstrates the importance of using in vivo systems to evaluate the metabolic remodelling in different tumour types.

\section{MATERIAL AND METHODS}

Human gene expression analysis

Oncomine $^{\mathrm{TM}}$ (Compendia Bioscience) was used to extract the top $5 \%$ upregulated genes in SCC from four databases. ${ }^{18-21}$ Twenty eight AdC and 58 SCC samples were analysed by Zhu et al. ${ }^{18}$; 65 normal lung samples, $45 \mathrm{AdCs}$ and 27 SCCs were analysed by Hou et al. ${ }^{19} ; 30$ AdCs and 155 SCCs were analysed from TCGA dataset ${ }^{20}$, and $127 \mathrm{AdCs}$ and 21 SCCs were analysed by Bhattacharjee et al. ${ }^{21}$ Genes that overlapped in at least three of the four databases were analysed by Panther Pathway Analysis. ${ }^{22}$ Hierarchical clustering or principal component analysis (PCA) was performed on microarrays from the Hou database ${ }^{19}$ using Cluster (Michael Eisen of UC Berkley) and Java Treeview $^{23}$ or SimcaP (MKS Data Analytics), respectively. Central carbon metabolism enzymes were filtered based on the gene having a GO Molecular Function of catalytic activity and a GO Biological Process term related to sugar, amino acid, nucleotide or energy metabolism. To determine whether Notch was active in a tissue, a thresholding method was employed. Gene expression was normalised to the median expression in the normal lung tissue. Notch was considered active if 4 of 5 Notch targets (HES1, HES2, HEY1, HEY2 and NRARP) ${ }^{24}$ were overexpressed by 1SD of the NC's median. This gave an $a=0.046$ for the Notch signature. Heat maps were exported from Oncomine $^{T M}$. KM plots were generated using Kaplan-Meier Plotter. ${ }^{25}$ JetSet best probes were used for the 24 SCC metabolic signature genes or the Notch targets above and patients were split based on expression in the upper tertile.

Additionally, AdC and SCC patient RNA-seq gene expression data were downloaded from the Genomic Data Commons (GDC) repository using the TCGA biolinks R/Bioconductor package. ${ }^{26}$ Only the harmonised data were selected. The data set contained 59 normal tissue samples from AdC patients and 49 from SCC patients, $535 \mathrm{AdC}$ and 502 SCC samples. Associated clinical data were also downloaded from the GDC repository. Three read counts matrices were build using the AdC and SCC samples. Read counts were normalised and transformed using variancestabilising transformation (VST) using the DESeq2 R/Bioconductor package. ${ }^{27}$ VST counts matrix was filtered with the 25 genes signature (in contrast to microarray data the expression of CKTM1A and CKMT1B genes was quantified separately). Z-scores were computed, which were used to generate the heatmaps using the ComplexHeatmap R/Bioconductor package ${ }^{28}$ with the clustering default parameters. Principal Component Analyses (PCA) was performed on the VST counts matrix for the 25 genes signature. The first 10 principal components were used to perform ANOVA of a tumour stage. The Benjamini-Hochberg procedure $^{29}$ was applied on the ANOVA $p$ values to control the FDR.
Human tissue SIRM

Lung cancer patients with suspected primary lung cancer but without diagnosed diabetes were recruited on the basis of surgical eligibility according to an IRB-approved protocol as previously described. ${ }^{30}$ Patients were overnight-fasted $(>8 \mathrm{~h})$ and then randomly grouped into two cohorts. In one of the cohorts, patients were administered $10 \mathrm{~g}\left[\mathrm{U}-{ }^{13} \mathrm{C}\right]$-glucose intravenously and preoperatively $2.8 \pm 0.5 \mathrm{~h}$ prior to VATS wedge resection. Another cohort did not receive a glucose injection. The extent of resection was determined by the surgeon according to clinical criteria. Most of the specimens were obtained from wedge resections to minimise surgical times while the remainder was acquired in $<5$ min after the pulmonary vein was clamped; both practices helped avoid development of significant ischaemia in resected tissues. Immediately after resection, the tumour was transected and sections of cancerous and surrounding NC lung tissue at least 2 $\mathrm{cm}$ away from the tumour were biochemically quenched by flash freezing in liquid nitrogen. The margins of the tumour were initially assessed by the surgeon via visual inspection. Parallel tissue samples were sent to on-site pathologists for confirmation of diagnosis and cancer-free margin. The remaining specimen was preserved in buffered formalin for detailed pathological examination.

The tissues from both groups of patients were used for metabolomics analysis. Additionally, some tissues from both groups were thin sliced using a Weck microtome $(0.5-1 \mathrm{~mm}$ thick, $0.5-1 \mathrm{~cm}^{2}$ area) in the operating room. These slices were immediately placed in T25-flasks containing $8 \mathrm{~mL}$ DMEM with the appropriate tracer (either $10 \mathrm{mM}{ }^{13} \mathrm{C}$-glucose, $2 \mathrm{mM}$ glutamine or $10 \mathrm{mM}$ glucose and $2 \mathrm{mM}\left[\mathrm{U}-{ }^{13} \mathrm{C}, \mathrm{U}-{ }^{15} \mathrm{~N}\right]$-glutamine) and $10 \%$ dialysed foetal bovine serum (FBS), and then transferred to a $\mathrm{CO}_{2}$ incubator set to $37^{\circ} \mathrm{C}$ and $5 \% \mathrm{CO}_{2}$ as previously described. ${ }^{31}$ The flasks were continuously rocked for $24 \mathrm{~h}$ for aeration and to maintain constant nutrient supplies at the tissue surface, while avoiding local build-up of waste products such as lactate. The slices were then washed in cold PBS and frozen in liquid nitrogen.

The frozen tissue samples were pulverised to $<10 \mu \mathrm{m}$ particle size in liquid nitrogen using a freezer mill (Spex). Metabolites were extracted from the ground powder with a 2:1.5:1 ratio of acetonitrile:water:chloroform giving a total volume of $4.5 \mathrm{~mL}$ followed by centrifugation for $20 \mathrm{~min}$ at $4000 \times g$ at $4{ }^{\circ} \mathrm{C}$. This afforded a two-phase partition, separated by insoluble protein residue. The polar phase was aliquoted and lyophilised for analysis by NMR and GC-MS. The NMR fraction was dissolved in $350 \mu \mathrm{L} \mathrm{1-}$ $\mathrm{mM}$ perdeuterated EDTA in $\mathrm{D}_{2} \mathrm{O}$ containing $30 \mathrm{nmol} \mathrm{d}_{6}$-DSS. The GC-MS fraction was dissolved in $50 \mu \mathrm{L}$ water containing $50 \mathrm{nmol}$ norleucine internal standard and acidified with $33 \mu \mathrm{L} 40 \%$ trichloroacetic acid (TCA) to a final 10\% TCA concentration at $4{ }^{\circ} \mathrm{C}$. The sample was re-lyophilised, then brought up in $50 \mu \mathrm{L}$ 1:1 acetonitrile: $N$-(t-butyldimethylsilyl)- $N$-methyltrifluoroacetamide (MTBSTFA, Campbell Science) and sonicated for $3 \mathrm{~h}$, followed by overnight incubation at RT. The protein residues were extracted by homogenisation in a $2 \%$ sodium dodecyl sulphate (SDS), $62.5 \mathrm{mM}$ Tris, and $1 \mathrm{mM}$ DTT, $\mathrm{pH} 6.8$ buffer for protein determination using the Pierce BCA method (ThermoFisher Scientific).

Media samples were deproteinise using acetone precipitation, followed by lyophilisation and dissolution in $\mathrm{D}_{2} \mathrm{O}$ containing DSS$\mathrm{d}_{6}$. NMR spectra were acquired at $20^{\circ} \mathrm{C}$ on a Varian Inova $14.1 \mathrm{~T}$ spectrometer (Varian, Inc.) equipped with a $5 \mathrm{~mm} \mathrm{HCN}$ cold probe (tissue extracts) or on an Agilent DD2 14.1T spectrometer equipped with a $3 \mathrm{~mm} \mathrm{HCN}$ cold probe (media extracts). 1D proton spectra were recorded with presaturation of the solvent resonance, an acquisition time of $2 \mathrm{~s}$, and a recycle time of $5 \mathrm{~s}$. 1D ${ }^{1} \mathrm{H}^{-13} \mathrm{C}$ HSQC spectra were recorded with acquisition times of $0.15 \mathrm{~s}$ in $t_{2}$. Spectral analysis was performed with MestReNova software (Mestrelab Research). Spectra were zero filled to $128 \mathrm{~K}$ points (presat) or 8k points (1D HSQC) and apodized with an unshifted Gaussian function and 1 ( ${ }^{1} \mathrm{H}$ NMR) or $6 \mathrm{~Hz}\left(1 \mathrm{D}{ }^{1} \mathrm{H}-{ }^{13} \mathrm{C}\right.$ HSQC) line 
broadening exponential. Chemical shifts were referenced to DSS at $0 \mathrm{ppm}$. After manual phase and baseline correction, peaks were integrated using the global deconvolution method of the software. Metabolites were identified based on chemical shifts as previously determined using 2D methodologies and comparisons to standard. ${ }^{29,30}$ Metabolites were quantified using the $-\mathrm{Si}-\left(\mathrm{CH}_{3}\right)_{3}$ DSS peak at $0 \mathrm{ppm}$ (for ${ }^{1} \mathrm{H}-\mathrm{NMR}$ ) or the $3-{ }^{13} \mathrm{C}$ lactate peak at $1.32 \mathrm{ppm}$ (for $\left.{ }^{1} \mathrm{H}-{ }^{13} \mathrm{C} \mathrm{HSQC}\right)$ as a reference.

GC-MS samples were analysed on a ThermoFinnigan PolarisQ GC-Ion trap MSn system (ThermoFisher Scientific). One microliter of sample injected (inlet $280^{\circ} \mathrm{C}$ ) onto a $5 \%$ phenyl capillary column ( $50 \mathrm{~m} \times 0.15 \mathrm{~mm} \times 0.25 \mu \mathrm{m}$ (SGE Forte, Victoria, Australia)) using $1.5 \mathrm{~mL} / \mathrm{min}$ helium as carrier gas. An oven temperature of $60^{\circ} \mathrm{C}$ was held for $2 \mathrm{~min}$, followed by gradients to $150^{\circ} \mathrm{C}\left(20^{\circ} \mathrm{C} / \mathrm{min}\right)$ and then $300^{\circ} \mathrm{C}\left(6^{\circ} \mathrm{C} / \mathrm{min}\right)$. The transfer line was held at $280^{\circ} \mathrm{C}$. The MS was operated in segment scan mode (scan ranges: 140-206, 209-280 and 283-650 m/z, scan-rate 1 scan per $0.97 \mathrm{sec}$. Metabolites were identified and quantified by comparison to the retention times, fragmentation patterns, and peak areas of authentic standards. Ion peaks were integrated using Xcalibur software (ThermoFisher Scientific). Quantifications were normalised to the internal standard norleucine.

\section{N1ICD and MYC overexpression}

The description of the transgenic mouse models used in this study has been previously published. ${ }^{24,32}$ Briefly, mice expressing rtTA under the control of the rat CCSP promoter were crossed with mice encoding N1ICD and MYC under the transcriptional control of a tetracycline-response element. The CCSP promoter was used to achieve lung-specific expression and mainly led to activation of N1ICD and MYC in the distal epithelium, presumably type 2 pneumocytes, as opposed to the Club cells of the bronchial epithelium. ${ }^{24}$ As previously reported by Allen and colleagues, the co-expression of MYC and N1ICD cooperates to produce papillary adenocarcinoma (PA) tumours within the alveolar epithelium.

\section{Mouse tissue SIRM}

Control and tumour-bearing male mice were given a bolus injection of $20 \mathrm{mg}\left[\mathrm{U}-{ }^{13} \mathrm{C}\right]$-glucose or $2 \times 7.2 \mathrm{mg}\left[\mathrm{U}-{ }^{13} \mathrm{C}\right]$-glutamine via tail vein $15 \mathrm{~min}$ prior to dissection as described previously. ${ }^{11}$ Lung tumours and normal lung were dissected and flash frozen in liquid nitrogen. Tissues were processed for NMR analysis as described for humans. For GC-MS analysis, metabolites from $\sim 1$ to $5 \mathrm{mg}$ of tissue were extracted with $400 \mu \mathrm{L}$ ice-cold chloroform and $200 \mu \mathrm{L}$ methanol. Samples were vortexed for $30 \mathrm{~s}$ and metabolites extracted by pulse sonication for $1 \mathrm{~h}$. Samples were centrifuged for $30 \mathrm{~min}$ at $21,000 \times g$ and $4^{\circ} \mathrm{C}$. The supernatant was collected, and the tissue pellet was resuspended in $400 \mu \mathrm{L}$ methanol and $200 \mu \mathrm{L}$ water containing $5 \mathrm{nmol}$ norleucine. Metabolites were reextracted as above, and the two supernatants were combined and dried. Metabolites were phase-partitioned using 3:3:1 methanol: water:chloroform ( $\mathrm{v} / \mathrm{v})$ and subsequent centrifugation $(21,000 \times g$, $4{ }^{\circ} \mathrm{C}, 30 \mathrm{~min}$ ). Polar (upper) and apolar (lower) phases were separated by an interphase of insoluble protein.

Polar metabolites were dried and washed twice in methanol, followed by derivatizing overnight (RT) by methoxymation ( 20 $\mathrm{mg} / \mathrm{mL}$ methoxyamine-hydrochloride in pyridine (both SigmaAldrich)) and subsequent trimethylsilylation (99:1 BSTFA+TMS (Supelco Analytical)) for more than $1 \mathrm{~h}$, before injection onto the GC-MS. Proteins were extracted from the insoluble residue by homogenisation in a 2\% SDS, $62.5 \mathrm{mM}$ Tris, and $1 \mathrm{mM}$ DTT, pH 6.8 buffer for protein determination using the Pierce BCA method (Thermo Fisher Scientific).

Polar metabolite extracts were analysed by GC-MS (Agilent 7890A-5975C), as previously described. ${ }^{33}$ Identification, abundance and label incorporation of individual metabolites was estimated as previously described. ${ }^{34}$
Percent enrichment calculations

The level of enrichment of individual isotopologues $(m+x)$ of metabolites was estimated as the percentage of the metabolite pool containing $\times{ }^{13} \mathrm{C}$ atoms after correction for natural abundance:

Enrichment of $\mathrm{m}+\mathrm{x}=\frac{\mathrm{Cm}+\mathrm{x}}{\sum \mathrm{Cm}+0+\mathrm{Cm}+1 \ldots+\mathrm{Cm}+\mathrm{i}} \times 100 \%$

$\%$ carbons enriched for a metabolite with $\mathrm{i}$ isotopologues was calculated by:

${ }^{13} \mathrm{Cmet}=\frac{m+1}{i}+2 \frac{m+2}{i} \ldots+\mathrm{i} \frac{m+i}{i}$

qPCR

RNA was isolated from frozen, ground lung and tumour tissues with TRI Reagent (Sigma). Genomic DNA with degraded with DNAfree kit (Ambion, Life Technologies). Total RNA was measured, and cDNA was generated following the manufacture's protocol for the High-Capacity cDNA Reverse Transcription Kit (ThermoFisher Scientific) and using $25 \mu \mathrm{g}$ of RNA in a final volume of $50 \mu \mathrm{L}$. RT qPCR reactions were carried out for all genes of interest using TaqMan Gene Expression Assays (ThermoFisher Scientific) on a ViiA 7 RT PCR System (ThermoFisher Scientific). In each $20 \mu \mathrm{L}$ TaqMan reaction, $1 \mu \mathrm{L}$ cDNA (corresponding to $50 \mathrm{ng}$ RNA) was mixed with $1 \mu \mathrm{L}$ TaqMan Gene Expression Assay and $10 \mu \mathrm{L}$ Taqman Universal PCR Master Mix (Applied Biosystems) and $8 \mu \mathrm{L}$ water. All reactions were run in duplicate and $C_{t}$ values for the genes of interest were normalised to the reference gene $18 \mathrm{~s}$.

Electrophoresis and western blotting

Proteins were extracted from the frozen tissue or cells harvested via trypsinization by homogenisation in a $2 \%$ SDS and $62.5 \mathrm{mM}$ Tris and were heat-denatured at $90^{\circ} \mathrm{C}$ for $10 \mathrm{~min}$, then centrifuged at $21,000 \times g$ for $30 \mathrm{~min}$ at $4{ }^{\circ} \mathrm{C}$. Protein extracts were mixed with a loading buffer give a final concentration of $10 \%$ glycerol, $2 \%$ SDS, $60 \mathrm{mM}$ Tris $\mathrm{pH} 6.8,0.01 \%$ bromophenol blue and $10 \% \beta-$ mercaptoethanol. Approximately $20 \mu \mathrm{g}$ protein per sample was then loaded on a $10 \%$ Acrylamide SDS-PAGE gel with a $6 \%$ stacking gel and subjected to electrophoresis for $\sim 2 \mathrm{~h}$ at $80 \mathrm{~V}$ in $0.3 \%$ Trizma Base, $1.44 \%$ glycine and $0.1 \%$ SDS. The separated proteins were transferred to a nitrocellulose membrane (BioRad) by blotting at $400 \mathrm{~mA}$ for $2 \mathrm{~h}$ at $4{ }^{\circ} \mathrm{C}$ in $0.3 \%$ Trizma Base, $1.44 \%$ Glycine, $0.005 \%$ SDS and $20 \%$ methanol.

Protein loading was assessed by incubating the blot in $0.1 \%(\mathrm{w} / \mathrm{v})$ Ponceau $\mathrm{S}$ red in $5 \%$ acetic acid for $5 \mathrm{~min}$, followed by rinsing in water. The blot was blocked for $1 \mathrm{~h}$ at RT in $5 \%$ powdered milk in phosphate buffered saline plus $0.1 \%$ Tween-20 (PBST) and incubated overnight at $4{ }^{\circ} \mathrm{C}$ in an appropriate dilution of the primary antibody:

MYC (1:1000, 1472-1, Epitomics)

Notch (1:500, ab4990, Abcam)

HES1 (1:750, ab71559, Abcam)

GAPDH (1:5000, 2118s, Cell Signaling)

TPI (1:500, ab135532, Abcam)

PSAT (1:500, 20180-1-AP, Protein Tech)

PHGDH (1:1000, sc292792, Santa Cruz)

ME1 (1:1000, ab97445, Abcam)

ME2 (1:500, ab139686, Abcam)

GOT1 (1:250, ap2947a, Abgent)

GOT2 (1:500, ab93928, Abcam)

IDH1 (1:1000, 12332-1-AP, Protein Tech)

IDH2 (1:2000, ab55271, Abcam)

ASNS (1:500, 1732, Epitomics)

Actin (1:50,0000, A2228, Sigma)

After rinsing, the membranes were incubated for $1 \mathrm{~h}$ at RT in a 1:5000 dilution of an appropriate secondary antibody, e.g. horseradish peroxidase (HRP) conjugated goat anti-mouse or 
54

anti-rabbit IgG (Santa Cruz). Finally, after incubation with chemiluminescent HRP substrate (Amersham ECL Prime Western Blotting Detection Reagent, GE Healthcare).

Statistical analysis

Significance in gene expression for the human microarray data was determined using one-way ANOVA with Tukey correction for multiple comparisons between tissue groups, followed by Bonferroni correction for multiple comparisons of different genes. For the human metabolic data, AdC and SCC tumours were compared to their paired NC counterparts using the paired Student's $t$-test. To test for significance between AdC and SCC, the Welch $t$-test was performed on the log-ratio of the tumour to matched normal. For mouse gene expression, significance was determined by Welch's $t$-test. The Bonferroni correction for multiple comparisons of different genes was not conducted because the analysis was restricted to planned comparisons based on genes found to be significant from the human microarray. For the mouse metabolic data, $M Y C+N 1 / C D$ tumours were compared to NC lung from age-matched littermates using the Welch $t$-test. All statistical tests were two-tailed. All statistical tests were calculated using Prism (GraphPad).

\section{RESULTS}

Human lung SCCs and AdCs have distinct metabolic gene expression profiles

In order to determine which biological processes distinguish SCCs from NC lung tissues and lung carcinomas of different histotypes, we used Oncomine ${ }^{\mathrm{TM}}$ to extract the top $5 \%$ genes upregulated in SCCs in comparison with NC tissues and/or AdCs from four databases $^{18-21}$ (Fig. S1a). Genes that overlapped in at least three of the four databases were analysed by PANTHER Gene Ontology. ${ }^{22}$ Genes encoding proteins with enzymatic activity, including metabolic enzymes, constituted the bulk of overlapping genes (Fig. S1b, Table S1).

We then asked whether the expression of enzymes that participate in central carbon metabolism alone was sufficient to distinguish SCCs from NC lung and AdCs. Hierarchical Clustering (Fig. 1a, Fig. S2a) and PCA (Fig. 1b, Fig. S2a) were performed on samples from the Hou et al. database ${ }^{19}$ because it contained a large cohort of NC lung samples and allowed us to compare the metabolic reprogramming in different NSCLC histotypes relative to benign lung. We used only those genes that encode enzymes of amino acid, carbohydrate, nucleotide, energy or one-carbon metabolism. Hierarchical clustering readily segregated normal from cancer tissues. The tumour cluster contained a sub-cluster of SCC tumours (Fig. 1a). Accordingly, by PCA, cancerous tissues were well resolved from $\mathrm{NC}$ lung in the first principal component (PC1) and SCCs were resolved from AdCs in PC3 (Fig. S2a). Twenty-four genes were (1) responsible for the separation of SCCs in PCs 1 and 3 by PCA as determined by the loadings plot; (2) were found within the two gene clusters revealed by hierarchical clustering with higher expression in SCC tumours than in NC and AdC and (3) were statistically overexpressed in SCC relative to NC. Twenty of these 24 genes were also statistically overexpressed in SCC relative to AdC tissues after Bonferroni correction (Fig. 1c). The differential pattern of changes in the expression of these genes between AdC and SCC tumours relative to NC lungs suggests metabolic reprogramming in NSCLC is histology specific.

We verified the increased expression of the 24-metabolic gene signature in SCCs relative to AdCs or NC and AdCs (where the gene expression data for NC samples were available) in additional databases (Fig. S2a) and TCGA RNA-seq data set (Fig. S3a). Figure 1c shows how 23 of the 24 genes map in the metabolic network. These are genes for enzymes involved in glycolysis (ALDOC, GAPDH, TPI and PGAM), the pentose phosphate pathway
(G6PDH, TALDO1), nucleotide biosynthesis (CTPS1, GMPS, UMPS and PAICS), serine biosynthesis/one carbon metabolism (PSAT1, SHMT2, MTHFD2 and AHCY), glutathione biosynthesis (GCLM, GGH and GSS), the malate-aspartate shuttle/Krebs cycle (GOT2, IDH2, $\mathrm{MDH} 2$ and ME1), creatine metabolism (CKMT1), butyrate metabolism (BDH1) and asparagine metabolism (ASNS). Together these data show that primary SCC and AdC tumours reprogramme metabolic gene expression differently. Importantly, the 24-gene signature correlates with the stage of the disease (Fig. S3b) and high expression of this 24-gene signature is predictive of a worse overall survival in NSCLC and SCC patients (Fig. S3c).

Given the different expression of metabolic genes, we then sought to determine whether this was associated with changes in the SCC metabolome. We analysed paired cancer and noncancerous tissues from 39 patients with resectable tumours. Metabolites were measured by gas-chromatography mass spectrometry (GC-MS) and nuclear magnetic resonance (NMR) spectroscopy. PCA was performed using 55 identified and quantified metabolites from matched pairs of tissues. PCA was able to separate lung tumours from NC lungs (Fig. 1d). Furthermore, pairs of tumour and adjacent benign lung tissues from the same patient did not cluster together. This indicates that the changes in metabolism associated with NSCLC tumorigenesis are more distinct than the metabolic differences between individuals due to age, sex, race, genetic make-up or environmental factors such as smoking history.

Similar to the PCA based on metabolic gene expression (Fig. 1b), the PCA based on metabolites (Fig. 1d) suggest that SCC tumours have a more distinct metabolic phenotype from NC tissues than AdC. We also performed PCA on the expression of genes encoding metabolic enzymes used above for primary AdCs and SCCs from Hou database ${ }^{19}$ and commercially available cell lines established from NSCLC patients from the Broad Institute Cancer Cell Line Encyclopedia. ${ }^{35}$ Unlike the primary tumours, which separated in PC1 based on histotype, in vitro cultured cell lines did not (Fig. 1e). These results suggest that cell lines no longer display the metabolic gene signature of their parent histotypes. Indeed, of the 21 genes with available data in the Broad-Novartis Cancer Cell Line Encyclopedia, only BDH1 was significantly elevated in SCC cell lines relative to ADC cell lines (Fig. S2b).

Together these data show that primary SCC and AdC tumours have a distinct reprogramming of metabolic gene expression that is not preserved in established cells in culture.

Although mRNA expression provides important information about the regulation of metabolic pathways, it does not necessarily reflect enzymatic activity, which also depends on protein expression and post-translational modifications or allosteric regulation. ${ }^{35-37}$ Although total levels of metabolites can provide a snapshot of a metabolic state of a cell, they by themselves are not sufficient to infer about the activity of a metabolic pathway. Ultimately metabolic activity provides the evidence for whether the changes in genes or protein expression result in changed metabolism. To that end, we employed stable isotope tracers coupled with SIRM to assess the activity of several pathways implicated in the SCC-distinguishing metabolic signature.

Human lung SCCs display enhanced activity in pathways related to the metabolic gene signature

Four of the 10 glycolytic enzymes were in the SCC-distinguishing metabolic gene signature (Fig. 1c). In fact, for all 10 glycolytic enzymes, at least one isoform was significantly upregulated in SCCs relative to NC lung (Fig. S4a) and in seven of these, one isoform was significantly greater in SCCs than in AdCs.

To assess glucose utilisation, our NSCLC patients were grouped into two cohorts. In the first cohort $(n=15)$, patients were administered intravenously $10 \mathrm{~g}$ of uniformly ${ }^{13} \mathrm{C}$ labelled glucose ([U- $\left.{ }^{13} \mathrm{C}\right]$-glucose) $2.8 \pm 0.5 \mathrm{~h}$ prior to tumour resection. ${ }^{13,38}$ The 
a

All genes (18k probes)

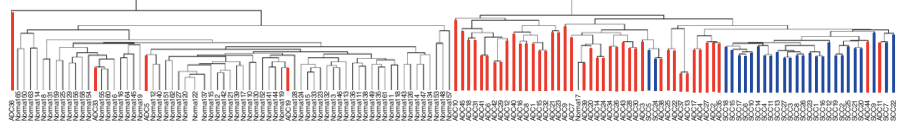

Central carbon metabolism enzymes (354 probes)

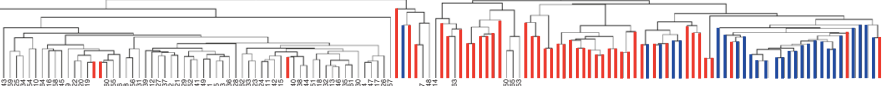

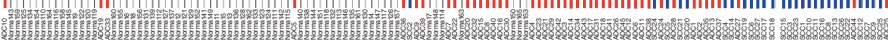

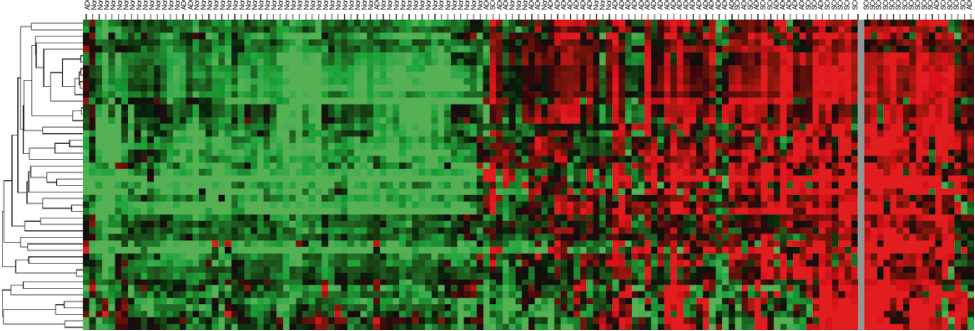

b

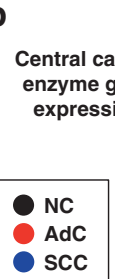

d

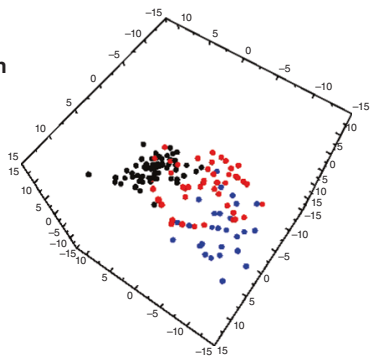

[Metabolite]

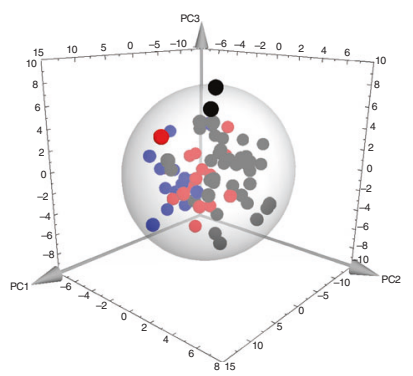

C

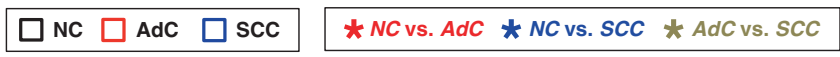

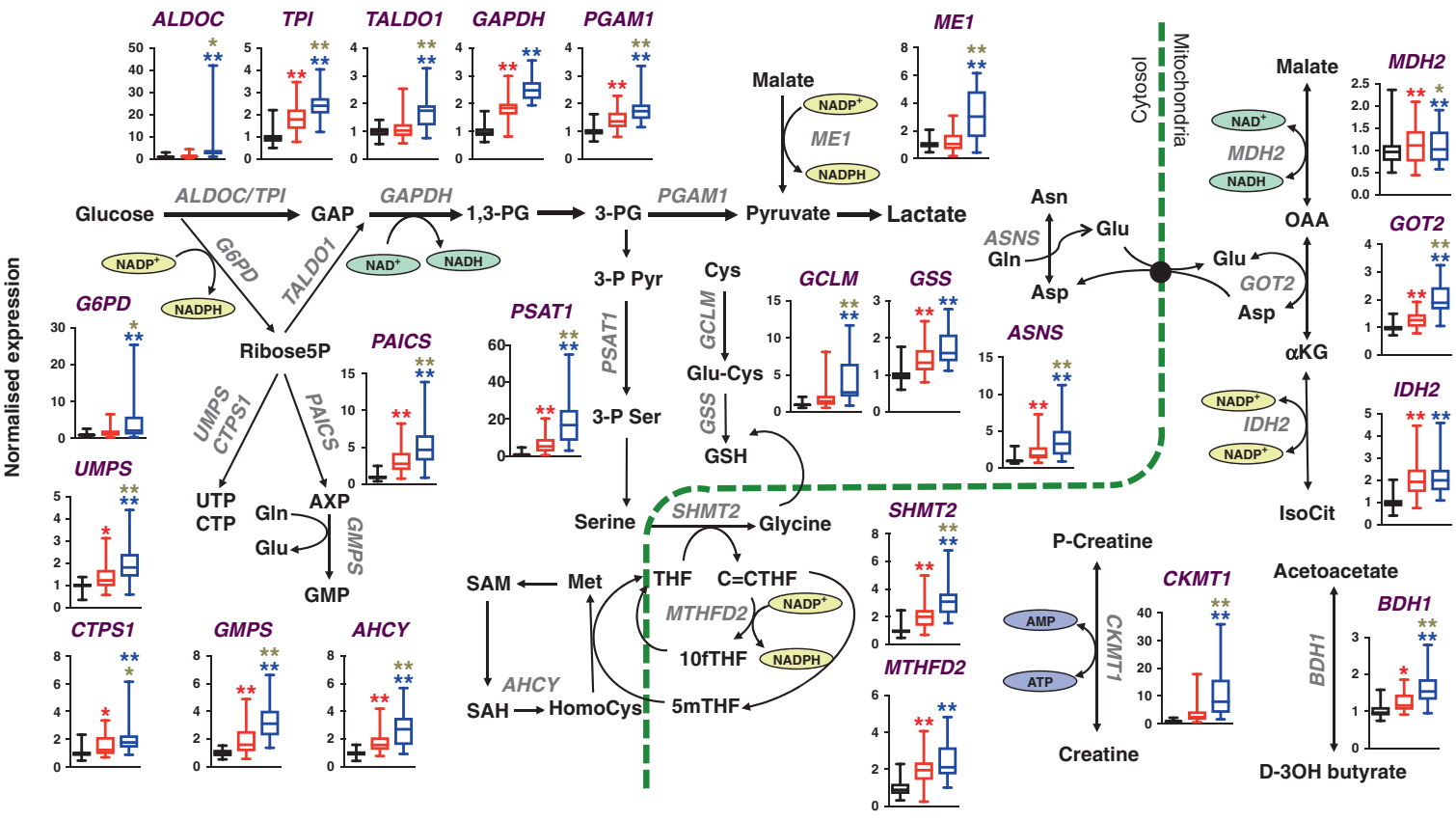

e

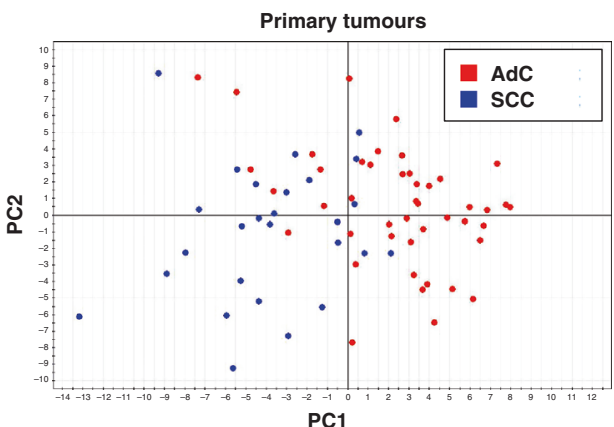

second cohort did not receive the $\left[\mathrm{U}-{ }^{13} \mathrm{C}\right]$-glucose infusion $(n=16)$. In order to accomplish a higher degree of labelling into downstream pathways and to decouple the tissue metabolism from systemic metabolism, ${ }^{31}$ freshly resected tissues from both cohorts were also prepared as thin slices and incubated with $\left[\mathrm{U}-{ }^{13} \mathrm{C}\right]$-glucose for $24 \mathrm{~h}$

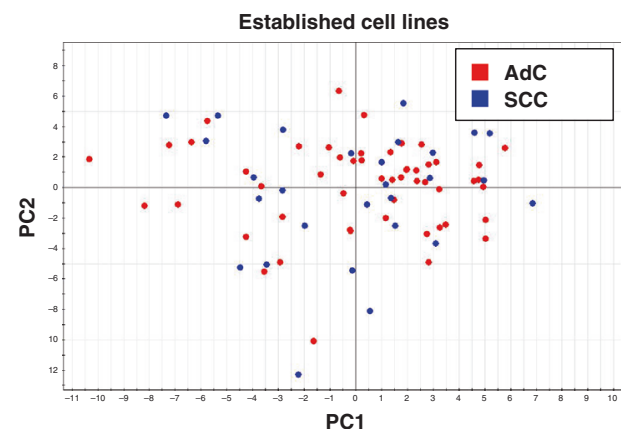

ex vivo. ${ }^{13}$ The ex vivo tissue slices also enabled the utilisation of more costly $\left[\mathrm{U}-{ }^{13} \mathrm{C}, \mathrm{U}-{ }^{15} \mathrm{~N}\right]$-glutamine as a tracer.

Plasma glucose enrichment was not different between SCC $(n=7)$ and $\operatorname{AdC}(n=5)$ patients post-infusion or peri-operatively (Fig. 2a). Tissues from both AdCs and SCCs had reduced levels of 
Fig. 1 Non-cancerous lung tissue (NC), adenocarcinomas (AdC) and squamous cell carcinomas (SCC) have distinct metabolic phenotypes. a: Hierarchical clustering of gene expression from AdC, SCC and NC lung using 18,000+probes or only probes for 354 enzymes in central carbon metabolism from the Hou database ${ }^{19}$ (see Fig. S2 for full heat map). b PCA of enzyme expression from the Hou database ${ }^{19}$ R2X[1] $=$ $22 \%, \mathrm{R} 2 \mathrm{X}[2]=8 \%$ and $\mathrm{R} 2 \mathrm{X}[3]=5 \%$. c 23/24 genes in the SCC-specific metabolic signature mapped onto their interconnecting pathways. Relative expressions are shown as box and whisker plots for AdCs $(n=45)$ and SCCs $(n=27)$, normalised to the median expression in NC tissues $(n=65)$. Whiskers represent min to max. One-way ANOVA with Tukey correction for multiple comparisons between tissue groups and Bonferroni correction for multiple comparisons of different genes. ${ }^{*} P<0.05$; ${ }^{* *} P$ value $<0.01$. See Table $S 2$ for $P$-values, $F$ values and degrees of freedom. d PCA performed on paired NC and tumours resected from human patients $(n=31)$ based on 55 metabolites measured by GC-MS and NMR R2X[1] $=33.2 \%, R 2 X[2]=13.6 \%$ and $R 2 X[3]=7.5 \%$. e PCA of the expression of enzymes in primary tumours (Hou database, top panel, $\mathrm{R} 2 \mathrm{X}[1]=12 \%, \mathrm{R} 2 \mathrm{X}[2]=8 \%$ ) and commercial cell lines (Cancer Cell Line Encyclopedia from the Broad Institute, bottom panel, $\mathrm{R} 2 \mathrm{X}[1]=$ $8 \%, \mathrm{R} 2 \mathrm{X}[2]=7 \%)$. See also Fig. S1-S3 and Table S2

a

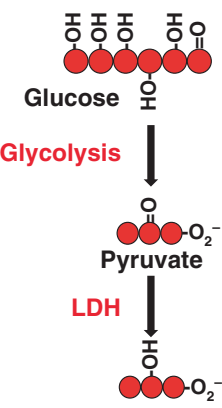

Plasma glucose (Postinfusion)

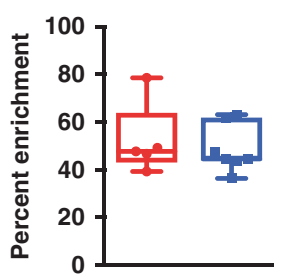

Plasma glucose

(Postoperative)

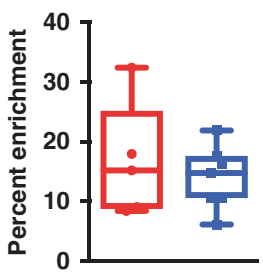

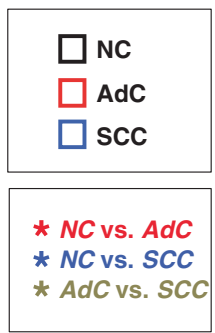

Lactate

b

Glucose

${ }^{13} \mathrm{C}_{6}$-Glucose

Lactate

${ }^{13} \mathrm{C}_{3}$-Lactate
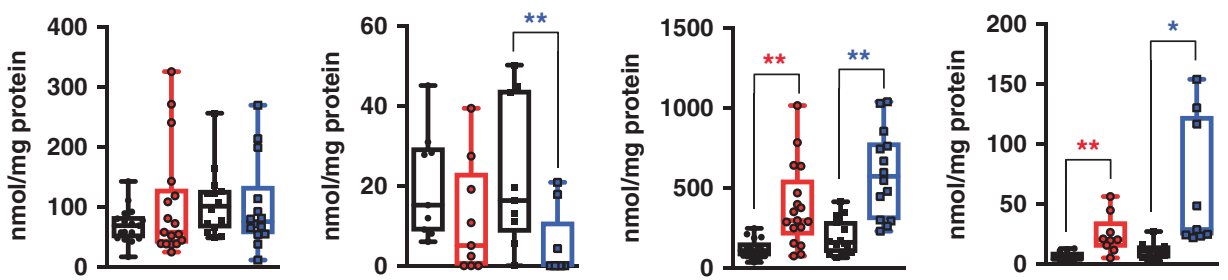

C

Glucose

${ }^{13} \mathrm{C}_{6}$-Glucose

Lactate

${ }^{13} \mathrm{C}_{3}$-Lactate

d

PET SUV
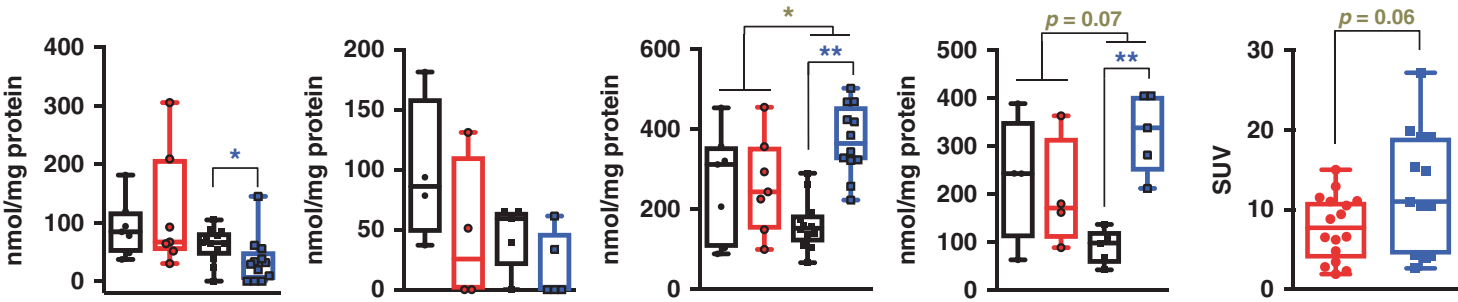

Fig. 2 SCC tumours produce more lactate from glucose than AdC or NC. a Plasma samples were taken immediately after the intravenous $\left[\mathrm{U}-{ }^{13} \mathrm{C}\right]$-glucose infusion (Postinfusion) and immediately after tumour resection (Postoperative). Plasma glucose enrichment was calculated from the ${ }^{13} \mathrm{C}$ satellite peaks and the unlabelled doublet for the anomeric carbon proton of $\alpha$-glucose from ${ }^{1} \mathrm{H}-\mathrm{NMR}$ spectra. b Total and labelled glucose and lactate concentrations from primary tumours calculated from the $\mathrm{H}-\mathrm{C} 3$ peak of lactate and the anomeric carbon proton of $\alpha$-glucose from the proton and ${ }^{1} \mathrm{H}\left\{{ }^{13} \mathrm{C}\right\}$ HSQC NMR spectra, respectively. $\mathbf{c}$ Total and labelled glucose and lactate measured from tissue slices incubated with $\left[\mathrm{U}^{13} \mathrm{C}\right]$-glucose for $24 \mathrm{~h}$ ex vivo. For total concentration of glucose and lactate the values are combined for both groups of slices incubated with either $\left[\mathrm{U}-{ }^{13} \mathrm{C}\right]$-glucose or $\left[\mathrm{U}-{ }^{13} \mathrm{C}, \mathrm{U}-{ }^{15} \mathrm{~N}\right]$-glutamine. d SUV of FDG-PET in SCC and AdC patients. See also Fig. S4 and Table S3

${ }^{13} \mathrm{C}$-glucose and greater levels of ${ }^{13} \mathrm{C}$-lactate than paired adjacent $\mathrm{NC}$ lung as measured by ${ }^{1} \mathrm{H}\left({ }^{13} \mathrm{C}\right)$ heteronuclear single quantum coherence (HSQC) NMR and GC-MS (Fig. 2b and S4b), indicating that these tumours convert more glucose to lactate than NC lung. SCC tissue slices also maintained higher concentrations of total and ${ }^{13} \mathrm{C}$-enriched lactate than AdCs (Fig. 2c and S3d), which is consistent with increased levels of lactate observed in SCC tissue samples previously. ${ }^{16}$ Interestingly, levels of total and ${ }^{13} \mathrm{C}$-enriched lactate in NC lung tissue from SCC patients were also higher than those in NC lung resected from AdC patients (Fig. 2b). It is likely that lactate measured in the NC lung of SCC patients is at least in part derived from the tumours, as there was no increase in lactate production among NC tissues slices cultured ex vivo, while SCC tissue slices produced more lactate than their paired NC slices or AdC slices (Fig. 2c). Achieving a higher production of ${ }^{13} \mathrm{C}$-glucosederived lactate in SCCs relative to AdCs would require both higher glucose catabolism and glucose transport. Consistently, higher standard uptake values (SUV) of ${ }^{18} \mathrm{~F}$-fluorodeoxyglucose as measured by FDG-PET were observed in SCCs from our patient cohort compared with AdCs (Fig. 2d). Previous studies have 
demonstrated that SCCs have higher FDG-PET SUV 39,40 as well as increased expression of glucose transporter 1 in comparison with AdCs. ${ }^{41,42}$

Beyond glycolysis, several enzymes in the SCC-distinguishing metabolic gene signature incorporate glucose carbons into metabolites of other pathways (Fig. 3a), and thus lactate may not be the only major destination for glucose carbon in SCC. For example, SCCs had increased expression of PPP enzymes G6PD and TALDO1 and de novo nucleotide biosynthesis enzymes UMPS, CTPS, PAICS and GMPS compared to NC and AdC tissues (Fig. 1d). Higher rates of PPP and purine biosynthesis in SCCs were supported by the fact that in vivo ${ }^{13} \mathrm{C}$ incorporation into the ribose subunit of adenine nucleotides (AXP) was observed in 3 out of 9 SCC, but only 1 out of 9 AdC, and was not observed in the NC counterparts (Fig. 3b). In the ex vivo tissue slices, ${ }^{13} \mathrm{C}$ incorporation into AXP was observed in all but 2 NC tissues and this incorporation was increased in SCC but not in AdC slices over their paired NC tissues (Fig. 3c).

SCCs, but not AdCs, had increased concentrations of serine and glycine compared to paired NC tissues (Fig. S5a), which corresponded with the higher expression of PSAT and SHMT2 in SCCs over NC and AdCs (Fig. 1c). In addition, SCCs but not AdCs overexpress 2 other enzymes in the serine biosynthetic pathway (PHGDH and PSPH, Fig. S5b). Since labelled serine and glycine were difficult to detect in vivo we turned to the tissue slice model. Serine biosynthesis from $\left[\mathrm{U}^{13} \mathrm{C}\right]$-glucose or $\left[\mathrm{U}^{13} \mathrm{C}, \mathrm{U}-{ }^{15} \mathrm{~N}\right]$-glutamine is expected to produce serine with $3{ }^{13} \mathrm{C}$ atoms or $1{ }^{15} \mathrm{~N}$ atom, respectively (Fig. 3d). The percentage enrichment of both was increased in SCC but not in AdC tumour slices in comparison with paired NC (Fig. 3e, f), but statistical significance was only observed with $\left[\mathrm{U}-{ }^{13} \mathrm{C}, \mathrm{U}-{ }^{15} \mathrm{~N}\right]$-glutamine as tracer (Fig. $3 \mathrm{f}$ ).

The expression of two enzymes of de novo glutathione biosynthesis, GCLM and GSS, was higher in SCCs than in NC lungs and AdCs (Fig. 1c). Since ${ }^{13} \mathrm{C}$ labelled glutathione was undetectable in vivo, it was measured in $\left[\mathrm{U}-{ }^{13} \mathrm{C}\right]$-glucose-treated tissue slices by HSQC NMR. We observed ${ }^{13} \mathrm{C}$ enrichment in the C4-glutamate moiety of glutathione (GSH+GSSG) in all but one of the paired NC slices. SCC but not AdCs tissues had significantly increased median concentration of ${ }^{13} \mathrm{C}-4-\mathrm{GSH}+\mathrm{GSSG}$ relative to paired NC despite comparable amounts of the ${ }^{13} \mathrm{C}$ glutamate precursor (Fig. $3 \mathrm{~g}$ ). Increased levels of glutathione were also previously observed in SCCs versus AdCs tissues. ${ }^{16}$

Glucose can label the glutamate residue of glutathione via entry of glucose-derived pyruvate into the Krebs cycle (Fig. 3a). As previously reported, ${ }^{13,14}$ NSCLCs oxidise more glucose through the Krebs cycle than NC lung in vivo (Fig. 3h and S6a for full isotopologue distributions). In addition, the percentage ${ }^{13} \mathrm{C}$ enrichment of ${ }^{13} \mathrm{C}$-glucose-derived Krebs cycle intermediates was higher in ex vivo SCC than in ex vivo AdC tissue slices (Fig. $3 \mathrm{i}$ and $\mathrm{S} 6 \mathrm{~b}$ for full isotopologue distributions).

The mitochondrial components of the malate-aspartate shuttle were also important for the separation of SCCs from NC lung and AdCs (Fig. 1c). In fact, GOT2 was one of the most significantly overexpressed genes in every database (Fig. S1a). To track transaminase activity, slices were incubated with $\left[\mathrm{U}-{ }^{13} \mathrm{C}_{1}^{15} \mathrm{~N}\right]$ glutamine. The incorporation of ${ }^{13} \mathrm{C}$ into malate and aspartate reflects glutamine entry into the Krebs cycle, which was similar for all tissue types $(\mathrm{m}+4$ in Fig. $4 a)$. However, SCCs but not AdCs tissues showed higher enrichment of aspartate containing five heavy atoms relative to paired NC lung (albeit not statistically significant), which reflects the incorporation of $4{ }^{13} \mathrm{C}$ atoms (via oxaloacetate) plus $1{ }^{15} \mathrm{~N}$ atom from $\left[\mathrm{U}-{ }^{13} \mathrm{C},{ }^{15} \mathrm{~N}\right]$-glutamine-derived glutamate via GOT activity ${ }^{43}$ (Fig. $4 a$ ).

As indicated by the percentage enrichment of ${ }^{13} \mathrm{C}_{4}$-malate and -aspartate (Fig. 4a), oxidative glutamine catabolism was comparable among the tissue types. This was also evident for ${ }^{13} \mathrm{C}_{4}$-citrate (Fig. 4b). Interestingly, SCCs, but not AdCs, had greater percent enrichment in ${ }^{13} \mathrm{C}_{5}$-citrate than the paired $\mathrm{NC}$ lung, possibly the result of reductive carboxylation (Fig. 4b), which could be a consequence of the overexpression of IDH2 in the SCCdistinguishing gene signature (Fig. S2a).

Increased Notch activity in lung SCC correlates with the altered metabolic phenotype

Signalling pathways are known to play key roles in tumorigenesis and metabolic reprogramming. To elucidate which signalling pathways co-occur with the metabolic phenotype in SCCs, we used PANTHER Pathways and found that four pathways were enriched. The Notch pathway was the most over-represented at a 5 -fold enrichment (Table S1) in SCCs compared with NC lungs and AdCs, as many of the Notch effectors and downstream targets were consistently present in the top $5 \%$ upregulated genes in SCCs (Fig. S1a). Amongst the samples in the Hou et al. database, ${ }^{19}$ Notch ligands JAG1 and JAG2 and downstream targets HES1, HES2, $H E Y 1, H E Y 2^{44}$ and $M Y C^{45}$ are elevated in SCC tissues over NC lungs and AdCs (Fig. 5a). This tendency was observed in all databases (Fig. S7a, c). Notch activation was assessed in individual samples based on the expression of downstream targets (see Experimental Procedures) and was highly associated with SCC (Fig. 5b). Further, we found a high correlation between the expression of Notch pathway components and SCC-distinguishing metabolic genes (shown in black in Fig. S7b). Reanalysing data from a rigorous study that performed immunohistochemistry on 49 NSCLC patients with an antibody against the Notch1 intracellular domain (N1ICD) and quantified scoring based on its expression in the nucleus ${ }^{46}$ revealed that N1ICD is associated with SCC (Fig. 5c). Intriguingly, the Bhattacharjee et al. ${ }^{21}$ transcriptomics database had a cohort of AdCs that had increased expression of downstream Notch targets in comparison with NC lungs and the rest of AdC samples. These AdC samples also had increased expression of the 24-metabolic gene signature (highlighted in the purple box Fig. S7c) and may represent adeno-squamous tumours or adenocarcinomas with more SCC phenotype.

Elevated Notch target expression was not observed in SCC relative to AdC cell lines (Fig. $5 d$ ). Nevertheless, cells with high Notch signalling had higher expression of 10/21 SCCdistinguishing metabolic signature genes available in the BroadNovartis Cancer Cell Line Encyclopedia (Fig. 5e).

The relationship between Notch and the expression of metabolic genes is preserved in mouse lung tumour model

Ectopic overexpression of $N 1 / C D$ in the mouse lung alveolar epithelium leads to the formation of adenomas with an increased Myc level and, after a long latency period, adenocarcinomas. ${ }^{24}$ The tumorigenicity of N1ICD can be augmented by the cooverexpression of $M Y C^{24}$ We used this mouse model to investigate the relationship between $\mathrm{NOTCH}$ activation and metabolic reprogramming in NSCLC.

We evaluated the expression of 22 of the genes in the SCCdistinguishing metabolic gene signature in $M Y C+N 1 / C D$ tumours by qPCR. We found that 21 genes were overexpressed in the MYC $+N 1 / C D$ mouse tumours compared to NC lung from control mice (doxycycline-free diet; Fig. 6a). Among the 24-signature enzymes of human SCCs, 11 have isoforms. In most cases, one isoform is overexpressed in SCCs compared to NC lungs and AdCs (ALDOC, BDH1, CKMT1, CTPS1, GOT2, ME1, PGAM1 and SHMT2, Fig. S8). In all but SHMT, MyC+N1/CD tumours upregulated the SCCdistinguishing isoform. Furthermore, both isoforms of $\mathrm{MDH}$ and MTHFD were elevated in SCCs compared with NC lungs and were upregulated in $M Y C+N 1 / C D$ tumours. However, isocitrate dehydrogenase did not behave the same between the human and mouse tumours. IDH2 was upregulated in both human SCCs and AdCs, whereas all three isoforms were upregulated in $M Y C+N 1 / C D$ tumours. In summary, human SCCs specifically upregulated nine isoforms relative to $\mathrm{NC}$ and $\mathrm{AdC}$ tissues while $M Y C+N 1 / C D$ mouse tumours had the same isoform specificity in 8 out of 9 of these 

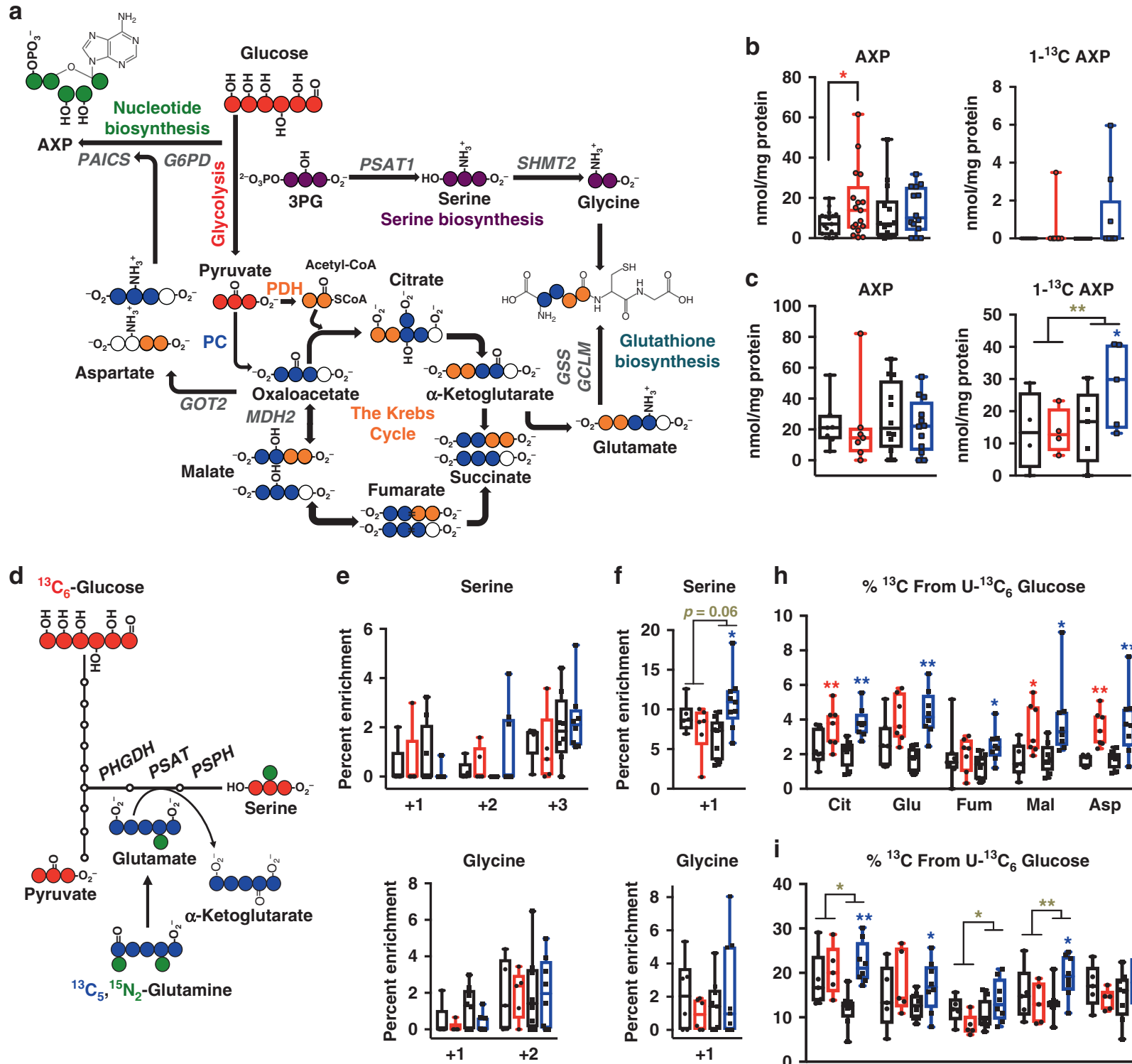

h $\quad{ }^{13} \mathrm{C}$ From $\mathrm{U}^{-13} \mathrm{C}_{6}$ Glucose

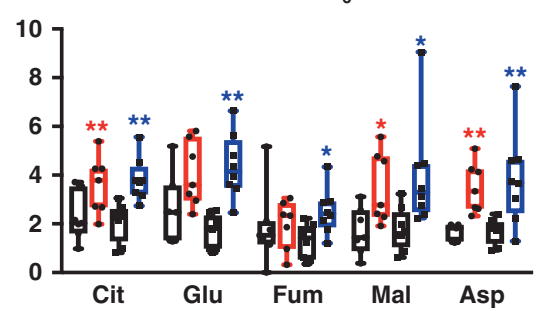

i $\quad{ }^{13} \mathrm{C}$ From U- ${ }^{13} \mathrm{C}_{6}$ Glucose
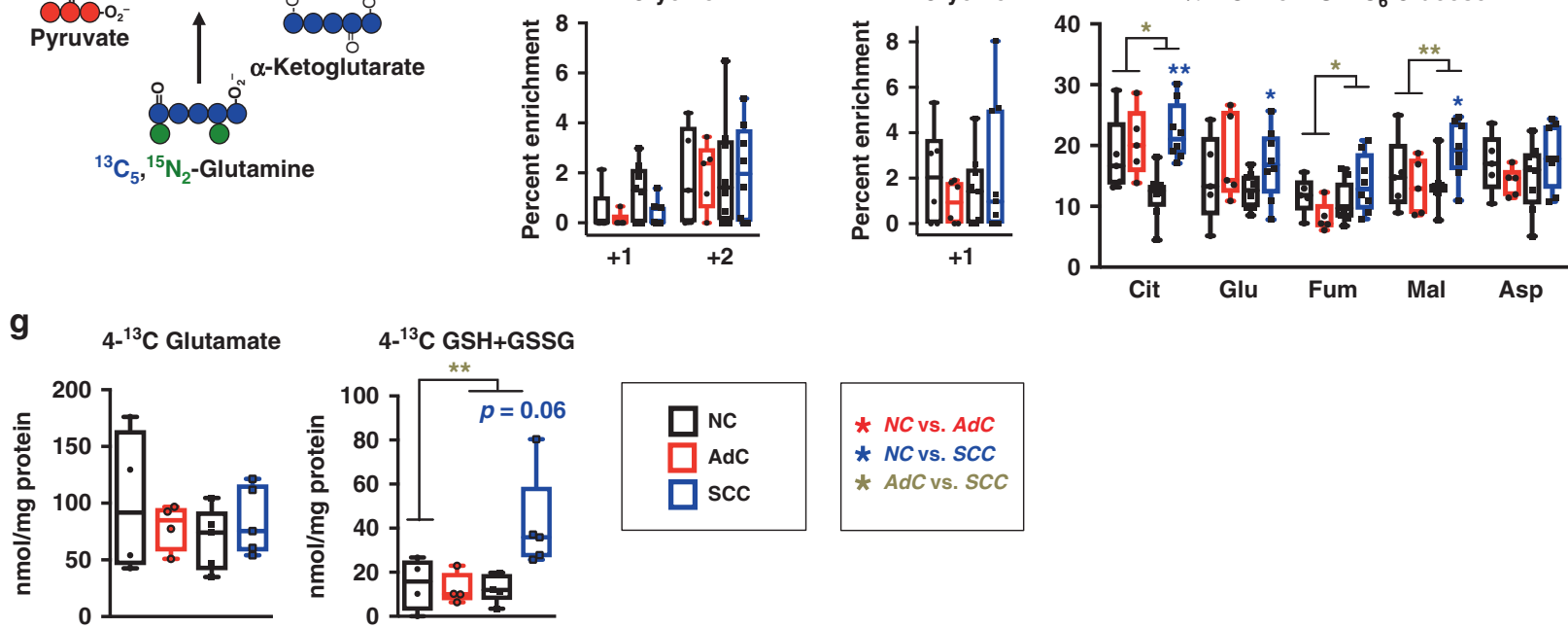

Fig. 3 SCC tumours input more glucose-derived carbon into nucleotides, the Krebs cycle, amino acids and glutathione. a A diagram showing how ${ }^{13} \mathrm{C}$ atoms from $\left[\mathrm{U}-{ }^{13} \mathrm{C}\right]$-glucose could be incorporated into various metabolites. $\mathbf{b}$ Levels of total and labelled adenine-containing nucleotides (AXP) calculated from the $\mathrm{C} 1$ position of the ribose moiety on the proton and ${ }^{1} \mathrm{H}\left\{{ }^{13} \mathrm{C}\right\} \mathrm{HSQC}$ NMR spectra, respectively in resected tumours from NSCLC patients who received a $\left[\mathrm{U}-{ }^{13} \mathrm{C}\right]$-glucose bolus; $c$ Levels of total and labelled AXP in tissues slices. Levels of $1-{ }^{13} \mathrm{C}$ AXP measured in tissue slices incubated with $\left[\mathrm{U}^{-13} \mathrm{C}\right]$-glucose ex vivo. Total levels of AXP are combined from both groups of slices incubated with either $\left[\mathrm{U}-{ }^{13} \mathrm{C}\right]$-glucose or $\left[\mathrm{U}-{ }^{13} \mathrm{C}, \mathrm{U}-{ }^{15} \mathrm{~N}\right]$-glutamine. $\mathbf{d}$ A diagram showing how $\left[\mathrm{U}-{ }^{13} \mathrm{C}, \mathrm{U}-{ }^{15} \mathrm{~N}\right]$-glutamine would produce ${ }^{15} \mathrm{~N}_{1}$-Serine. e, $\mathbf{f}$ Percent enrichment of serine and glycine isotopologues measured from tissues slices incubated with $\left[\mathrm{U}-{ }^{13} \mathrm{C}\right]-$ glucose $(\mathbf{e})$ or $\left[\mathrm{U}-{ }^{13} \mathrm{C}, \mathrm{U}-{ }^{15} \mathrm{~N}\right]-\mathrm{glutamine}(\mathbf{f})$. g Labelled isotopomer concentrations of glutamate and glutathione $(\mathrm{GSH})$ measured from the $\mathrm{C}-4$ peak of glutamate on the ${ }^{1} \mathrm{H}\left\{{ }^{13} \mathrm{C}\right\} \mathrm{HSQC}$ NMR spectra acquired from tissues slices incubated with $\left[\mathrm{U}-{ }^{13} \mathrm{C}\right]$-glucose. $\mathbf{h}$, i Percent enrichment of citrate (Cit), glutamate (Glu), fumarate (Fum), malate (Mal) and aspartate (Asp) isotopologues measured in resected tumours from NSCLC patients receiving a [U- ${ }^{13} \mathrm{C}$-glucose bolus (h) and tissues slices incubated with $\left[\mathrm{U}-{ }^{13} \mathrm{C}\right]$-glucose (i). Data are shown as box and whisker plots where whiskers represent the min and max. ${ }^{*} P<0.05$ and ${ }^{* *} P<0.01$. AdC and SCC tumours were compared to their paired NC counterparts using the paired $t$-test. To test for significance between AdC and SCC, the Welch t-test was performed on the log-ratio of the tumour to their paired NC. See also Fig. S5, S6 and Table S4 
a

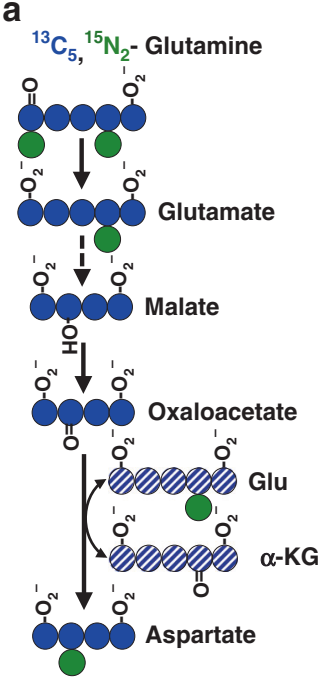

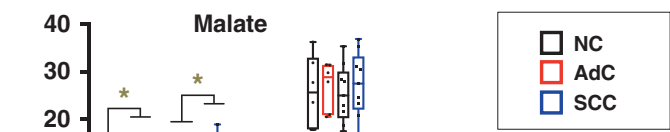

* NC vs. AdC

* NC vs. SCC

* AdC vs. SCC

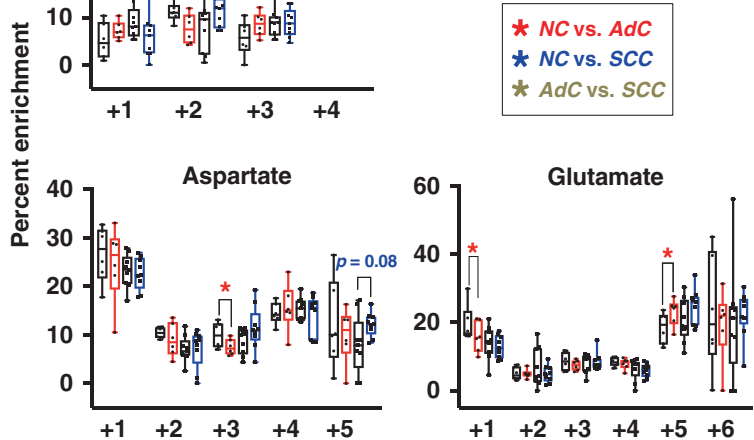

b

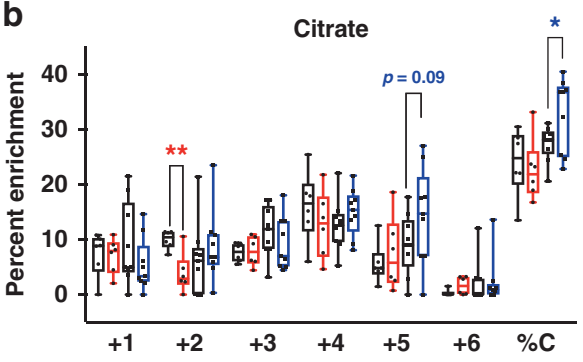

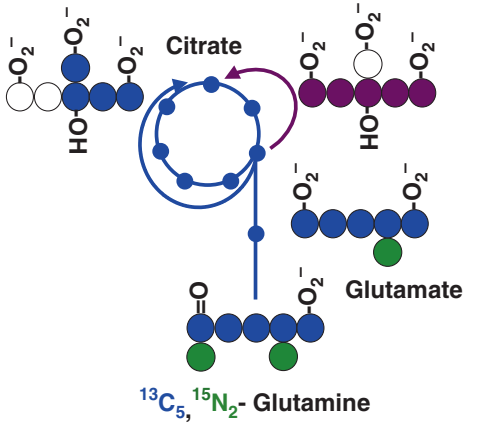

Fig. $4 \mathrm{SCC}$ tumours catabolise glutamine via transaminase reactions and reductive carboxylation. a $\mathrm{A}$ diagram shows how $\left[\mathrm{U}-{ }^{13} \mathrm{C}, \mathrm{U}-{ }^{15} \mathrm{~N}\right]-$ glutamine would produce malate $\mathrm{m}+4$ and then aspartate $\mathrm{m}+4$ or $\mathrm{m}+5$. Percent enrichment of malate, glutamate and aspartate isotopologues in slices of tumours and NC lung incubated with $\left[\mathrm{U}-{ }^{13} \mathrm{C}, \mathrm{U}-{ }^{15} \mathrm{~N}\right]$-glutamine for $24 \mathrm{~h}$. b Percent enrichment of citrate Isotopologues from slices in a. A diagram shows $\left[\mathrm{U}-{ }^{13} \mathrm{C}, \mathrm{U}-{ }^{15} \mathrm{~N}\right]$-glutamine would produce citrate $\mathrm{m}+4$ and $\mathrm{m}+5$. Data are shown as box and whisker plots where whiskers represent the min and max. ${ }^{*} P<0.05$ and ${ }^{* *} P<0.01$. AdC and SCC tumours were compared to their paired NC counterparts using the paired or Welch $t$-test, respectively. To test for significance between AdC and SCC, the Welch $t$-test was performed on the log-ratio of the tumour to their paired NC. See also Table S5

cases, which further supports an association between Notch activation and the SCC-distinguishing metabolism.

Since MYC is a well-known regulator of cellular metabolism, 47,48 we next evaluated how much it might contribute to the changes in the expression of metabolic genes downstream of NOTCH. We analysed murine tumours driven by MYC alone. ${ }^{32}$ Out of 21 metabolic genes for 13 genes involved in the Krebs cycle, one carbon metabolism and nucleotide and glutathione biosynthesis, the co-expression of MYC and N1ICD led to the overexpression that was not significant in the MYC-only tumours and for 3 genes it enhanced the over-expression that was less pronounced in the MYC-only tumours (Fig. 6a). However, the expression of glycolytic and serine biosynthesis enzymes in $M Y C$-only tumours was similar to $M Y C+N 1 / C D$ tumours. These results demonstrate that, although MYC can significantly contribute to the metabolic remodelling downstream of NOTCH, complete activation of the NOTCH pathway quantitatively upregulates the SCC gene signature more than MYC alone.

We next evaluated how gene expression of selected metabolic genes translates into protein expression in $M Y C+N 1 / C D$ tumours. For 7 SCC-distinguishing enzymes (ASNS, GAPDH, GOT2, IDH2, ME1, PSAT, and TPI) protein levels were increased in $M Y C+N 1 / C D$ tumours compared with the normal lungs (Fig. 6b and S9a). We also assessed the isoform pattern for GOT, ME, and IDH (Fig. S9b). The IDH1 and IDH2 protein expression patterns (Fig. S9b) were consistent with the increased expression of IDH1 and IDH2 mRNAs (Fig. S8). However, GOT1, whose mRNA expression was non- significantly increased, and $M E 2$, which showed no change at the mRNA level (Fig. S8), were increased at the protein level by 3.0and 2.9-fold, respectively (Fig. S9b).

To test how NOTCH activation affects glycolysis in NSCLC, mice bearing $M Y C+N 1 / C D$-driven lung tumours received one bolus injection of $\left[\mathrm{U}-{ }^{13} \mathrm{C}\right]$-glucose $15 \mathrm{~min}$ before tumour resection. Tumours were compared to NC lungs from age-matched controls. Blood glucose enrichment was not significantly different (Fig. S10a) but tumours had higher total and ${ }^{13} \mathrm{C}$-lactate levels than NC lung (Fig. $6 \mathrm{C}$ and $\mathrm{S} 10 \mathrm{~b})$. We further examined $\left[\mathrm{U}-{ }^{13} \mathrm{C}\right]$-glucose metabolism in $M Y C+N 1 / C D$ mouse tumours. Consistent with the increased expression of PSAT (Fig. 6a, b), MYC+N1/CD tumours had greater ${ }^{13} \mathrm{C}$ incorporation into ${ }^{13} \mathrm{C}_{1}$ - and ${ }^{13} \mathrm{C}_{2}$-serine (Fig. $6 \mathrm{~d}$ and $\mathrm{S} 10 \mathrm{c})$, presumably produced by the Ser/Gly exchange reaction catalysed by SHMT (see Fig. S5C for full description) from ${ }^{13} \mathrm{C}_{2^{-}}$ glycine than NC lung (Fig. $6 \mathrm{~d}$ ). $M Y C+N 1 / C D$ tumours also had increased glucose incorporation into the Krebs cycle, although the increase did not reach significance (Fig. 6e and S10d for full isotopologue distributions). Like SCCs, MYC $+N 1 / C D$ tumours had elevated levels of ${ }^{13} \mathrm{C}$ incorporation into the $4-{ }^{13} \mathrm{C}$ position of the glutamate residue of GSH+GSSG, despite having similar levels of the labelled glutamate precursor (Fig. 6f), which was consistent with the increased RNA levels of GSS (Fig. 6a).

When the $M Y C+N 1 / C D$ mice were injected with $\left[\mathrm{U}^{13} \mathrm{C}\right]-$ glutamine, blood glutamine enrichment was not significantly different (Fig. S11a) but Krebs cycle intermediates in MYC+N1ICD tumours showed increased percentage of ${ }^{13} \mathrm{C}$ enrichment, 


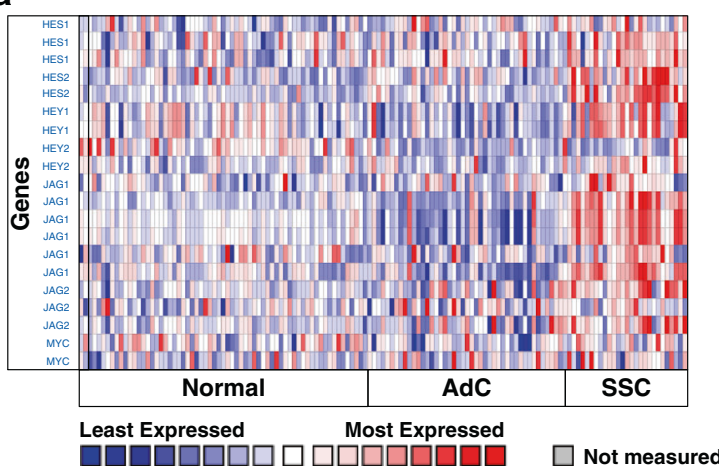

C

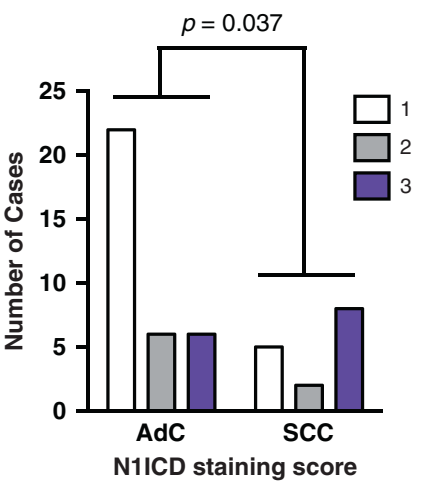

b

\begin{tabular}{|cccc|}
\hline Signature & Lung & ADC & SCC \\
\hline \multirow{2}{*}{ Notch } & $2 / 65$ & $1 / 45$ & $12 / 27$ \\
& $(3.1 \%)$ & $(2.2 \%)$ & $(44 \%)$ \\
\hline
\end{tabular}

d

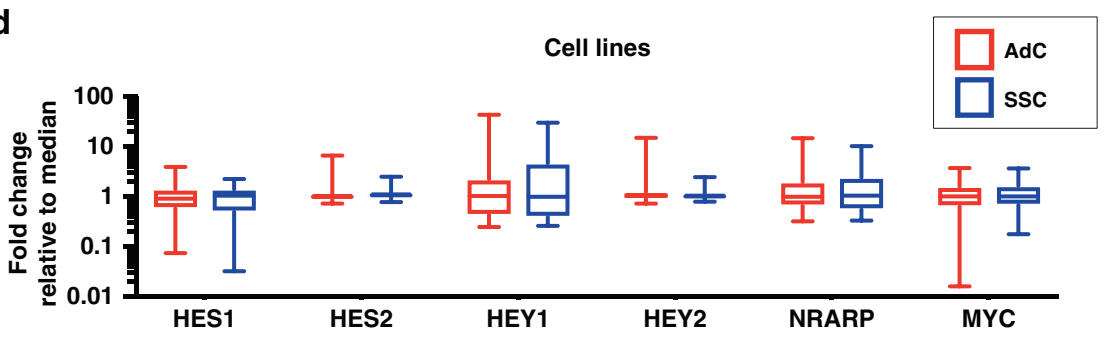

$\begin{array}{r}\square \text { Low Notch } \\ \square \text { High Notch } \\ \hline \text { Her }\end{array}$

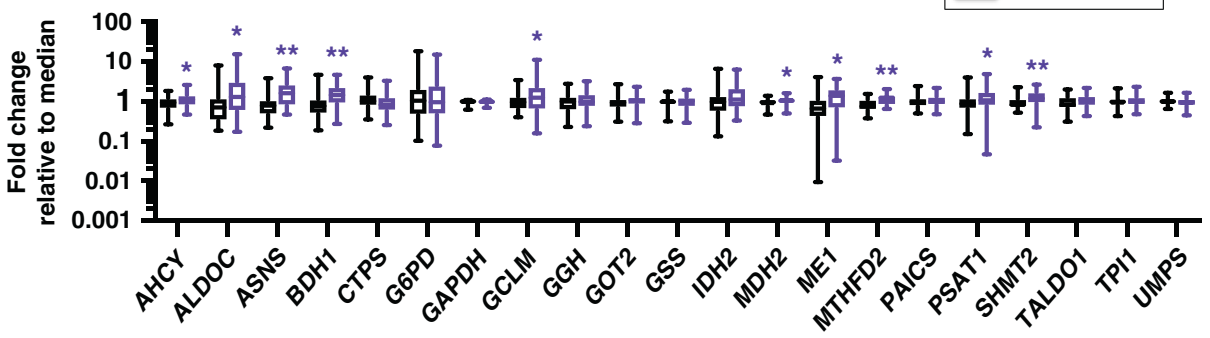

Fig. 5 Canonical Notch signalling pathway is upregulated in human lung SCC but not AdC and correlates with the SCC-specific metabolic genes. a A heat map of the expression of Notch downstream targets from the Hes and Hey families and MYC, along with Notch ligands of the Jag family in NC, AdC and SCC tissues from the Hou database. ${ }^{19}$ Corroborating heat maps from additional databases can be found in Fig. S7a, c. b Notch pathway activation in individual samples from the Hou database ${ }^{19}$ based on the expression of downstream Notch targets (see Experimental Procedures for full details). c Nuclear activated Notch1 (N1ICD) scoring in NSCLC tissues based on immunohistochemistry reanalysed from Westhoff et al. ${ }^{47}$ One is low expression and 3 is high. Fisher's Exact Test $\left(P=0.037, x^{2}=6.617\right.$ and $\left.d f=2\right)$. $\mathbf{d}$ The expression of downstream Notch targets assessed in AdC $(n=51)$ and SCC $(n=28)$ cell lines from the Broad-Novartis Cancer Cell Line Encyclopedia. Data are shown as box and whisker plots where whiskers show the min and max. ${ }^{*} P<0.05$ and ${ }^{*} P<0.01$. Significance was determined by twotailed $t$-test. e The expression of the SCC gene signature assessed in cell lines from the Broad-Novartis Cancer Cell Line Encyclopedia with low $(n=39)$ and high $(n=40)$ expression of downstream Notch targets. Data are shown as box and whisker plots where whiskers show the min and max. ${ }^{*} P<0.05$ and ${ }^{*} P<0.01$. Significance was determined by two-tailed $t$-test. See also Fig. S7, Table S6, S7

particularly for ${ }^{13} \mathrm{C}_{5}$-citrate (Fig. $6 \mathrm{~g}$ ), reminiscent of the SCC tissue slices (Fig. 4b). MYC + N1/CD tumours also displayed a greater catabolism of ${ }^{13} \mathrm{C}$-glutamine into ${ }^{13} \mathrm{C}_{4}$-fumarate and -malate (oxidative route, Fig. $6 \mathrm{~g}$ ) and ${ }^{13} \mathrm{C}_{3}$ - fumarate and -malate. The latter likely derived from ATP citrate lyase-catalysed cleavage of ${ }^{13} \mathrm{C}_{5}$-citrate produced via reductive carboxylation and/or malic enzyme activity on ${ }^{13} \mathrm{C}_{4}$-malate to produce ${ }^{13} \mathrm{C}_{3}$-pyruvate, which can be carboxylated to ${ }^{13} \mathrm{C}_{3}$-oxaloacetate by pyruvate carboxylase (Fig. S11b). This was reproduced in a second cohort of animals (Fig. S11c).
Together, the data support a relationship between NOTCH activation and the metabolic reprogramming observed preferentially in SCC. They also suggest that MYC can be one of the major mediators of the effect of NOTCH on the expression of metabolic genes. However, other signalling pathways likely cooperate or converge with Notch to meet the evolving metabolic requirements of tumour cells. Indeed, Notch1 expression and activity of Notch pathway was shown to be downstream of Nrf2, ${ }^{49,50}$ which is mutated in higher percentage of SCCs than ADCs ${ }^{51}$ and was shown to regulate the expression of metabolic enzymes. ${ }^{52}$ 
a D NC $\square$ mYc $\square$ MYC+N11CD * NC vs. MYc * NC vs. MYC+N11CD * MYC vs. MYC+N11CD

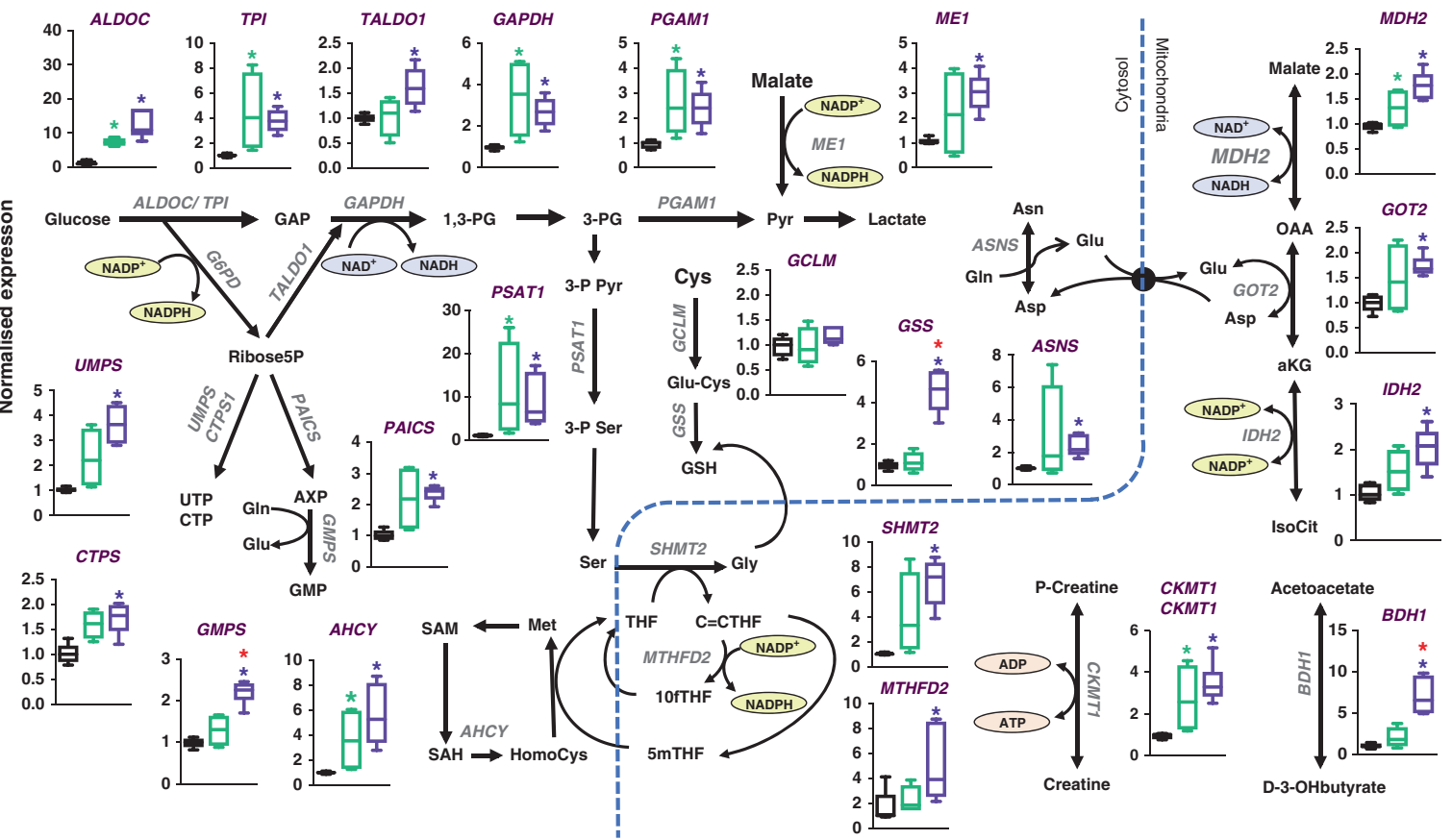

b

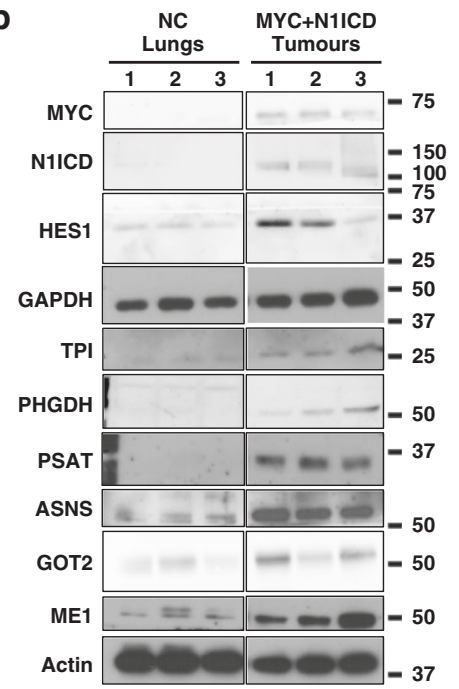

C
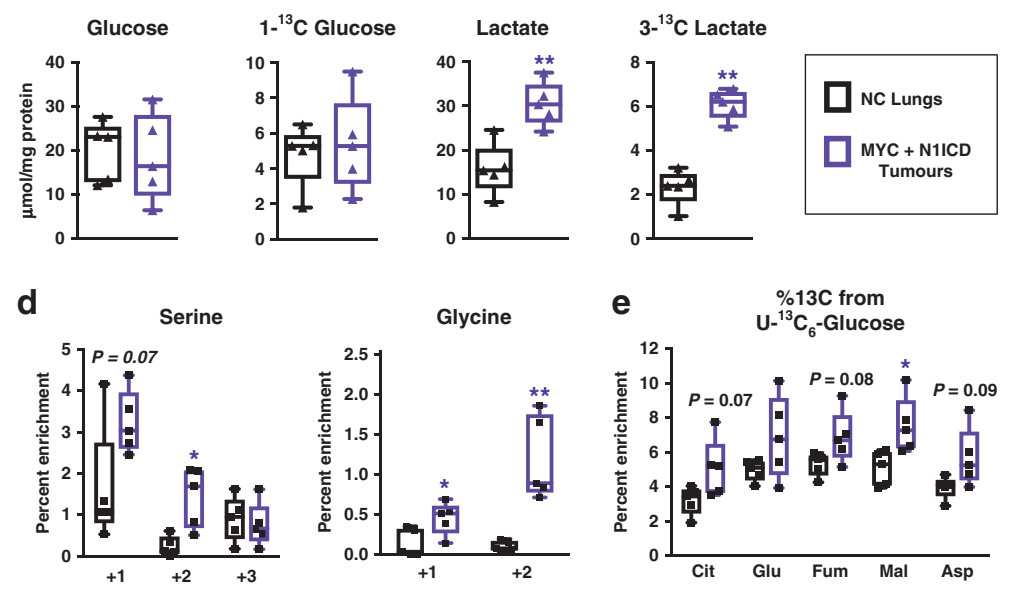
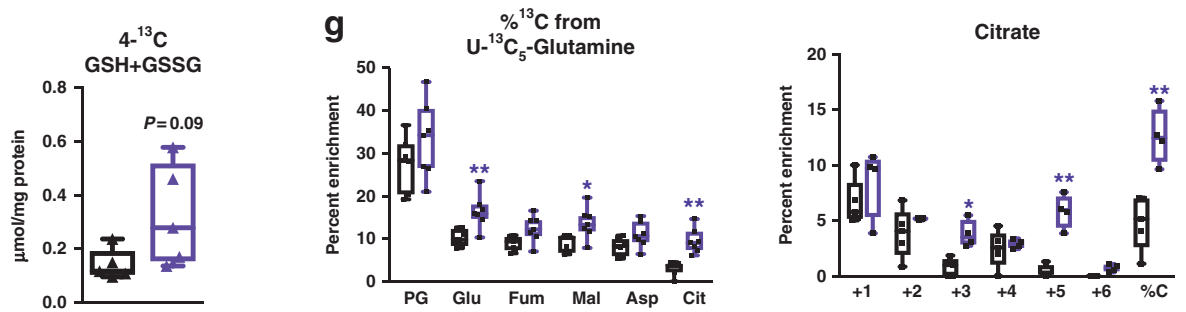

Together, our data point to a complex interaction between the tumour microenvironment, cell signalling and metabolism, emphasising the need to study lung cancer metabolism in vivo.

\section{DISCUSSION}

The integration of transcriptomic and metabolomic data revealed a metabolic reprogramming signature associated with
SCC. We show that SCCs had a more active catabolism of glucose carbon into a variety of pathways including glycolysis, the Krebs cycle, and nucleotide, amino acid and glutathione biosynthesis, which was supported by the higher expression of relevant enzymes. Our results demonstrate that the metabolic differences between subtypes are the result of the whole programme, which can be driven by Notch among other signalling pathways. 
Fig. 6 The relationship between Notch and the activity of metabolic pathways is preserved in N1ICD+MYC induced murine lung tumours. a Relative expression of metabolic genes measured by qPCR in $M Y C+N 1 / C D$ (purple bars, $n=6$ ), MYC tumours (green bars, $n=4$ ) and the NC lung of mice kept off doxycycline (black bars, $n=6$ ) are shown as box and whisker plots, Whiskers represent inner fences according to Tukey. b Protein expression of several enzymes from the SCC metabolic gene signature in MYC $+N 1 / C D$ tumours $(n=3)$ and NC lung $(n=3)$. The Welch's $t$-test; ${ }^{*} P<0.05$ and ${ }^{* *} P<0.01$. c Percent enrichment of serum glucose in $M Y C+N 1 / C D(n=5)$ tumour-bearing or control mice $(n=5)$ given a bolus injection of $\left[\mathrm{U}-{ }^{13} \mathrm{C}\right]$-glucose measured by GC-MS. The concentrations of Glc and Lac in the tumour or lung tissue were assessed by NMR as described above. $\mathbf{d}$ Percent enrichment of serine and glycine isotopologues measured in $M Y C+N 1 / C D$ tumours $(n=5)$ and control lung $(n=5)$ from mice injected with $\left[\mathrm{U}-{ }^{13} \mathrm{C}\right]$-glucose. e Percent enrichment of isotopologues of The Krebs cycle intermediates (citrate (Cit), glutamate (Glu), fumarate (Fum), malate (Mal) and aspartate (Asp)) in $M Y C+N 1 / C D$ tumours and control lung from mice injected with [U- $\left.{ }^{33} \mathrm{C}\right]-$ glucose. f Labelled isotopomer concentrations of glutamate and GSH measured in MYC+N1/CD tumours and control lung from mice injected with $\left[\mathrm{U}-{ }^{13} \mathrm{C}\right]$-glucose as above. g Metabolite isotopologues (pyroglutamate (PG), citrate (Cit), glutamate (Glu), fumarate (Fum), malate (Mal) and aspartate (Asp)) in tissues from MYC $+N 1 / C D$ tumour-bearing mice $(n=7)$ and NC controls $(n=7)$ injected with [U- $\left.{ }^{13} \mathrm{C}\right]-$ glutamine. Data are shown as box and whisker plots where whiskers show the min and max. ${ }^{*} P<0.05$ and ${ }^{* *} P<0.01$. MYC $+N 1 / C D$ tumours were compared to control lung using Welch $t$-test. See also Figs. S8, S9, S10, S11, Tables S8, S9

The activity of many metabolic pathways that distinguish SCC from AdC tumours, including glycolysis, PPP, the Krebs cycle and nucleotide biosynthesis, are required to support higher proliferation, as previously reported for SCC compared with AdC tumours. ${ }^{39,53,54}$ It is also consistent with both NOTCH1 and MYC being master regulators of cell proliferation. ${ }^{47,55}$ At the same time other differences, like higher reductive carboxylation of glutamine, may reflect differences in other cell autonomous functions or the tumour microenvironment.

For instance, these pathways not only provide the carbon for biosynthetic precursors but can also supply glutathione and the reducing equivalent NADPH for ROS detoxification (Fig. S12) and fatty acid synthesis. Moreover, both cytoplasmic and mitochondrial isoforms of GOT and MDH were elevated in the SCCs over NC lung and $\mathrm{AdCs}$, which suggests that these tumours have a higher activity of the malate-aspartate shuttle, possibly to maintain $\mathrm{NAD}^{+}$ homeostasis. The simultaneous increase in glycolytic and the Krebs cycle activity in SCC may require enhanced malate-aspartate shuttle to deliver NADH produced by glycolysis into the mitochondria for oxidation and to regenerate cytoplasmic $\mathrm{NAD}^{+}$ to support further glycolytic activity. ${ }^{56}$ Finally, we observed that glutamine contributed a substantial amount of carbon to the Krebs cycle in both normal lung and tumours; however, SCCs may catabolise glutamine reductively which should be investigated further with the appropriate tracer to evaluate its quantitative importance.

Our results also demonstrated that the Notch signalling pathway was highly enriched in SCCs and Notch activity correlated strongly with the observed metabolic phenotypes. However, the role of Notch in lung cancer is controversial. The Cancer Genome Atlas found that $8 \%$ of SCCs carry mutations in NOTCH1, half of which are predicted to be truncating suggesting a tumour suppressive function of Notch $1 .{ }^{20}$ This prediction is inconsistent with an earlier study that functionally characterised the 4 NOTCH1 mutations observed in their cohort NSCLC patients and concluded Notch mutations were gain-offunction. ${ }^{46}$ Notch 1 expression and activity in NSCLC has been extensively studied via immunohistochemical staining of human tumours and in vitro studies with established cell lines, with seemingly contradictory results (recently reviewed ${ }^{57}$ ). These studies typically assessed Notch staining both in the membrane/ cytoplasm and nucleus and therefore can only make limited conclusions with regards to the Notch transcriptional activity. This is in contrast to our study, which examined mRNA expression of downstream Notch targets and, therefore, should be more indicative of the Notch activity than the Notch 1 protein expression levels alone.

In our study, the oncogenic and metabolic function of Notch1 in human SCC was supported by the murine model $(M Y C+N 1 / C D)$ we used. While $N 1 / C D+M Y C$ tumours resembled the metabolic phenotype observed in human SCCs, comparing the expression of metabolic genes in $N 1 / C D+M Y C$ lung tumours and lung tumours induced by MYC alone showed that the expression of some signature enzymes was similar between the two types of tumours. This suggests that Notch is unlikely to directly regulate the expression of all 24-metabolic signature genes and that MYC can be one of the mediators of Notch's effect on metabolism in our models.

Lastly, differential regulation of metabolic pathways in NSCLC subtypes may suggest differential metabolic vulnerabilities and potential therapeutic targets. The metabolic gene signature might also explain the differential efficacy of gemcitabine over pemetrexed in SCC compared to AdC when paired with cisplatin ${ }^{58}$ and the preferred choice of combined gemcitabine and a platinum-based drug for first-line treatment of SCC patients. ${ }^{59}$ First, the chemotherapeutic agent gemcitabine is a potent competitive inhibitor of the SCC-signature enzyme CTPS1 and this activity may potentiate gemcitabine toxicity by amination of the inactive uracil metabolite $2^{\prime}$-deoxy- $2^{\prime}, 2^{\prime}$-difluorouridine triphosphate. $^{60}$ Secondly, the lower sensitivity of SCCs to pemetrexed, an anti-folate drug, has been suggested to be associated with the higher activity of another SCC-signature enzyme, GGH. ${ }^{61} \mathrm{GGH}$ hydrolyses the active polyglutamated version of pemetrexed.

As our signature may explain the differential efficacies of current standard of care chemotherapies, it may also reveal novel vulnerabilities. Higher expression of IDH2 together with higher reductive carboxylation of glutamine in SCCs in comparison with AdCs may suggest higher levels of ROS and consequent necessity for antioxidant protection. ${ }^{62}$ This is also consistent with increased levels of glutathione and GSS in SCCs but not in AdCs. Therefore, targeting both IDH2 and glutathione biosynthesis may prove to be efficient specifically in SCCs. Furthermore, the sensitivity of tumours to serine/glycine-deficient diet has recently been suggested to depend on their ability to synthesise serine and glycine from glucose. ${ }^{63}$ Increase in serine biosynthesis in SCCs but not in AdCs suggests that AdCs maybe more sensitive to a serine/ glycine deficient diet but at the same time SCCs may be addicted to serine biosynthesis.

Importantly, both the metabolic signature-based separation of SCC and AdC histotypes and association of increased Notch pathway activity in SCC tumours are lost in established cancer cell lines. Although recent data from Goodwin and co-authors demonstrate that AdC and SCC cell lines differ in their glucose catabolism, ${ }^{42}$ our results suggest that many metabolic aspects are lost in in vitro versus in vivo systems. This can be due to cells adapting to growing on plastic being exposed to nonphysiological concentrations of oxygen and nutrients or loss of intratumoral cellular interactions or both. Our results strongly argue that in vivo analyses of metabolism are required to understand the relationship between histotypes, metabolism and oncogenic drivers.

\section{ACKNOWLEDGEMENTS}

We would like to acknowledge Professor Gordon Stamp (University College London/ The Francis Crick Institute) for providing evaluation of cellularity of human tissues samples used for metabolomics analysis in this study. 


\section{AUTHOR CONTRIBUTIONS}

K.S., A.N.L., T. W.-M. F. and M.O.Y. conceived the study. M.B. performed the surgical resections. J.T. ground and extracted human tissues and performed tissue slice experiments. T.D.A. developed the mouse models. M.O.Y., T.D.A., A.M.-L., W.L. and K.S performed mouse experiments. J.I.M. and R.M.H. developed GC-MS methods. K.S. performed bioinformatics on human microarray data, prepared samples, acquired spectra, analysed MS and NMR data, performed qPCR, and interpreted the data. N.B. performed the analysis of RNA-seq data. Y.C. analysed protein expression in human samples. K.S. and M.O.Y. wrote the manuscript, which was edited by T.D.A., J.I.M., A. M.-L. and A.N.L.; R.M.H., A.N.L, T.W.-M.F. and M.O.Y. acquired the funding for this study.

\section{ADDITIONAL INFORMATION}

Supplementary information is available for this paper at https://doi.org/10.1038/ s41416-019-0464-z.

Competing interests: T.W.-M.F., A.N.L., R.M.H. and M.B. II declare that they have filed a US patent application entitled "Methods for Detecting Cancer" (US20130109592). T. D.A. is a co-founder of Tradewind BioScience Inc. However, the company's interest does not overlap with the work covered in the present manuscript.

Funding: This work was supported in part by National Science Foundation EPSCoR infrastructure grants EPS-0447479 (to T.W.-M.F.); NIH grants 5P01CA163223 (to A.N.L and T.W.-M.F) 1R01CA118434-01A2, 1RO1CA101199-01, 3R01CA118434-02S1 and 1R01ES022191-01 (to T.W.-M. F.), and 1U24DK097215-01A1 (to R.M.H., T.W.M.F. and A. N.L.); the University of Louisville CTSPGP/ARRA grant 20044; the Kentucky Lung Cancer Research Program grants OGMB090354B1 and OGMB101380 (to T.W.-M.F. and A.N.L.). This work was also supported by the Francis Crick Institute, which receives its core funding from Cancer Research UK (FC001223), the UK Medical Research Council (FC001223), and the Wellcome Trust (FC001223).

Data availability: The data sets generated during and/or analysed during the current study are available from the corresponding author on reasonable request.

Ethics approval and consent to participate: The study "Metabolomic Analysis of Tissue: A Translational Clinical Trial" was approved by the IRB committee of the University of Louisville (\#523.05). Written informed consent was obtained from all subjects prior to inclusion in this study. The study was performed in accordance with the Declaration of Helsinki. The animal experiments were conducted with the approval of either the Institutional Animal Care and Use Committee (IACUC) of the University of California, San Francisco or in accordance with United Kingdom regulations under project license PPLs 80/2623 and P609116C5.

Publisher's note: Springer Nature remains neutral with regard to jurisdictional claims in published maps and institutional affiliations.

\section{REFERENCES}

1. Ferlay, J., Steliarova-Foucher, E., Lortet-Tieulent, J., Rosso, S., Coebergh, J. W., Comber, $\mathrm{H}$. et al. Cancer incidence and mortality patterns in Europe: estimates for 40 countries in 2012. Eur. J. Cancer 49, 1374-1403 (2013).

2. Matsuda, T. \& Machii, R. Morphological distribution of lung cancer from Cancer Incidence in Five Continents Vol. X. Jpn J. Clin. Oncol. 45, 404 (2015).

3. Silva, A. P., Coelho, P. V., Anazetti, M., Simioni, P. U. Targeted therapies for the treatment of non-small-cell lung cancer: monoclonal antibodies and biological inhibitors. Hum. Vaccin. Immunother. 13, 843-853 (2017).

4. Fala, L. Portrazza (Necitumumab), an IgG1 monoclonal antibody, FDA approved for advanced squamous non-small-cell lung cancer. Am. Health Drug Benefits 9 (Spec Feature), 119-122 (2016).

5. Guo, L., Zhang, H., Chen, B. Nivolumab as Programmed Death-1 (PD-1) inhibitor for targeted immunotherapy in tumor. J. Cancer 8, 410-416 (2017).

6. Garon, E. B., Rizvi, N. A., Hui, R., Leighl, N., Balmanoukian, A. S., Eder, J. P. et al. Pembrolizumab for the treatment of non-small-cell lung cancer. N. Engl. J. Med. 372, 2018-2028 (2015).

7. DeBerardinis, R. J. \& Chandel, N. S. Fundamentals of cancer metabolism. Sci. Adv. 2, e1600200 (2016).

8. Hanahan, D. \& Weinberg, R. A. Hallmarks of cancer: the next generation. Cell 144, 646-674 (2011).

9. Soga, T. Cancer metabolism: key players in metabolic reprogramming. Cancer Sci. 104, 275-281 (2013).
10. Son, J., Lyssiotis, C. A., Ying, H., Wang, X., Hua, S., Ligorio, M. et al. Glutamine supports pancreatic cancer growth through a KRAS-regulated metabolic pathway. Nature 496, 101-105 (2013).

11. Yuneva, M., Zamboni, N., Oefner, P., Sachidanandam, R. \& Lazebnik, Y. Deficiency in glutamine but not glucose induces MYC-dependent apoptosis in human cells. J. Cell Biol. 178, 93-105 (2007).

12. Yuneva, M. O., Fan, T. W., Allen, T. D., Higashi, R. M., Ferraris, D. V., Tsukamoto, T. et al. The metabolic profile of tumors depends on both the responsible genetic lesion and tissue type. Cell Metab. 15, 157-170 (2012).

13. Sellers, K., Fox, M. P., Bousamra, M. 2nd, Slone, S. P., Higashi, R. M., Miller, D. M. et al. Pyruvate carboxylase is critical for non-small-cell lung cancer proliferation. J. Clin. Invest. 125, 687-698 (2015).

14. Hensley, C. T., Faubert, B., Yuan, Q., Lev-Cohain, N., Jin, E., Kim, J. et al. Metabolic heterogeneity in human lung tumors. Cell 164, 681-694 (2016).

15. Davidson, S. M., Papagiannakopoulos, T., Olenchock, B. A., Heyman, J. E., Keibler, M. A., Luengo, A. et al. Environment impacts the metabolic dependencies of rasdriven non-small cell lung cancer. Cell Metab. 23, 517-528 (2016).

16. Rocha, C. M., Barros, A. S., Goodfellow, B. J., Carreira, I. M., Gomes, A., Sousa, V. et al. NMR metabolomics of human lung tumours reveals distinct metabolic signatures for adenocarcinoma and squamous cell carcinoma. Carcinogenesis 36, 68-75 (2015).

17. Li, L., Wei, Y., To, C., Zhu, C. Q., Tong, J., Pham, N. A. et al. Integrated omic analysis of lung cancer reveals metabolism proteome signatures with prognostic impact. Nat. Commun. 5, 5469 (2014).

18. Zhu, C. Q., Ding, K., Strumpf, D., Weir, B. A., Meyerson, M., Pennell, N. et al Prognostic and predictive gene signature for adjuvant chemotherapy in resected non-small-cell lung cancer. J. Clin. Oncol. 28, 4417-4424 (2010).

19. Hou, J., Aerts, J., den Hamer, B., van ljcken, W., den Bakker, M., Riegman, P. et al. Gene expression-based classification of non-small cell lung carcinomas and survival prediction. PLOS ONE 5, e10312 (2010).

20. Cancer Genome Atlas Research Network. Comprehensive genomic characterization of squamous cell lung cancers. Nature 489, 519-525 (2012).

21. Bhattacharjee, A., Richards, W. G., Staunton, J., Li, C., Monti, S., Vasa, P. et al. Classification of human lung carcinomas by mRNA expression profiling reveals distinct adenocarcinoma subclasses. Proc. Natl Acad. Sci. USA 98, 13790-13795 (2001).

22. Mi, H., Muruganujan, A., Casagrande, J. T. \& Thomas, P. D. Large-scale gene function analysis with the PANTHER classification system. Nat. Protoc. 8, 1551-1566 (2013).

23. Saldanha, A. J. Java Treeview-extensible visualization of microarray data. Bioinformatics 20, 3246-3248 (2004).

24. Allen, T. D., Rodriguez, E. M., Jones, K. D. \& Bishop, J. M. Activated Notch1 induces lung adenomas in mice and cooperates with Myc in the generation of lung adenocarcinoma. Cancer Res. 71, 6010-6018 (2011).

25. Szasz, A. M., Lanczky, A., Nagy, A., Forster, S., Hark, K., Green, J. E. et al. Crossvalidation of survival associated biomarkers in gastric cancer using transcriptomic data of 1,065 patients. Oncotarget 7, 49322-49333 (2016).

26. Colaprico, A., Silva, T. C., Olsen, C., Garofano, L., Cava, C., Garolini, D. et al. TCGAbiolinks: an R/Bioconductor package for integrative analysis of TCGA data. Nucleic Acids Res. 44, e71 (2016).

27. Love, M. I., Huber, W. \& Anders, S. Moderated estimation of fold change and dispersion for RNA-seq data with DESeq2. Genome Biol. 15, 550 (2014).

28. Gu, Z., Eils, R. \& Schlesner, M. Complex heatmaps reveal patterns and correlations in multidimensional genomic data. Bioinformatics 32, 2847-2849 (2016).

29. Benjamini, Y. \& Hochhberg, Y. Controlling the false discovery rate: a practical and powerful approach to multiple testing. J. R. Stat. Soc. 57, 289-300 (1995).

30. Bousamra, M., Day, J., Fan, T. W.-M., Higashi, R. M., Kloecker, G., Lane, A. N., Miller, D. M. in The Handbook of Metabolomics. Methods in pharmacology and toxicology, 17. (eds Fan T. W.-M., Lane, A. N., Higashi, R. M.) (New York, Humana Press, 2012).

31. Fan, T. W., Lane, A. N. \& Higashi, R. M. Stable isotope resolved metabolomics studies in ex vivo tissue slices. Bio Protoc. 6, e1730 (2016).

32. Allen, T. D., Zhu, C. Q., Jones, K. D., Yanagawa, N., Tsao, M. S. \& Bishop, J. M. Interaction between MYC and MCL1 in the genesis and outcome of non-smallcell lung cancer. Cancer Res. 71, 2212-2221 (2011).

33. Saunders, E. C., Ng, W. W., Chambers, J. M., Ng, M., Naderer, T., Kromer, J. O. et al. Isotopomer profiling of Leishmania mexicana promastigotes reveals important roles for succinate fermentation and aspartate uptake in tricarboxylic acid cycle (TCA) anaplerosis, glutamate synthesis, and growth. J. Biol. Chem. 286, 27706-27717 (2011).

34. MacRae, J. I., Dixon, M. W., Dearnley, M. K., Chua, H. H., Chambers, J. M., Kenny, S. et al. Mitochondrial metabolism of sexual and asexual blood stages of the malaria parasite Plasmodium falciparum. BMC Biol. 11, 67 (2013). 
35. Alam, M. T., Olin-Sandoval, V., Stincone, A., Keller, M. A., Zelezniak, A., Luisi, B. F. et al. The self-inhibitory nature of metabolic networks and its alleviation through compartmentalization. Nat. Commun. 8, 16018 (2017).

36. Robles, M. S., Cox, J. \& Mann, M. In-vivo quantitative proteomics reveals a key contribution of post-transcriptional mechanisms to the circadian regulation of liver metabolism. PLoS Genet. 10, e1004047 (2014).

37. Zhao, S., Xu, W., Jiang, W., Yu, W., Lin, Y., Zhang, T. et al. Regulation of cellular metabolism by protein lysine acetylation. Science 327, 1000-1004 (2010).

38. Fan,T. W. M., Lane, A. N., Higashi, R. M., Farag, M. A., Gao, H., Bousamra, M. et al. Altered regulation of metabolic pathways in human lung cancer discerned by $\mathrm{C}$ 13 stable isotope-resolved metabolomics (SIRM). Mol Cancer 8, 41 (2009).

39. Vesselle, H., Salskov, A., Turcotte, E., Wiens, L., Schmidt, R., Jordan, D. et al. Relationship between non-small cell lung cancer FDG uptake at PET, tumor histology, and Ki-67 proliferation index. J. Thorac. Oncol. 3, 971-978 (2008).

40. Aquino, S. L., Halpern, E. F., Kuester, L. B. \& Fischman, A. J. FDG-PET and CT features of non-small cell lung cancer based on tumor type. Int J. Mol. Med. 19, 495-499 (2007).

41. Schuurbiers, O. C. J., Meijer, T. W. H., Kaanders, J. H. A. M., Looijen-Salamon, M. G., de Geus-Oei, L. F., van der Drift, M. A. et al. Glucose metabolism in NSCLC is histology-specific and diverges the prognostic potential of (18)FDG-PET for adenocarcinoma and squamous cell carcinoma. J. Thorac. Oncol. 9, 1485-1493 (2014).

42. Goodwin, J., Neugent, M. L., Lee, S. Y., Choe, J. H., Choi, H., Jenkins, D. M. R. et al. The distinct metabolic phenotype of lung squamous cell carcinoma defines selective vulnerability to glycolytic inhibition. Nat. Commun. 8, 15503 (2017).

43. Lane, A. N. \& Fan, T. W. Regulation of mammalian nucleotide metabolism and biosynthesis. Nucleic Acids Res. 43, 2466-2485 (2015).

44. Al-Hussaini, H., Subramanyam, D., Reedijk, M. \& Sridhar, S. S. Notch signaling pathway as a therapeutic target in breast cancer. Mol. Cancer Ther. 10, 9-15 (2011).

45. Palomero, T., Lim, W. K., Odom, D. T., Sulis, M. L., Real, P. J., Margolin, A. et al. NOTCH1 directly regulates c-MYC and activates a feed-forward-loop transcriptional network promoting leukemic cell growth. Proc. Natl Acad. Sci. USA 103, 18261-18266 (2006)

46. Westhoff, B., Colaluca, I. N., D'Ario, G., Donzelli, M., Tosoni, D., Volorio, S. et al. Alterations of the Notch pathway in lung cancer. Proc. Natl Acad. Sci. USA 106, 22293-22298 (2009).

47. Dang, C. V. MYC, metabolism, cell growth, and tumorigenesis. Cold Spring Harb. Perspect. Med. 3, a014217 (2013).

48. Zeller, K. I., Jegga, A. G., Aronow, B. J., O’Donnell, K. A. \& Dang, C. V. An integrated database of genes responsive to the Myc oncogenic transcription factor: identification of direct genomic targets. Genome Biol. 4, R69 (2003).

49. Wakabayashi, N., Shin, S., Slocum, S. L., Agoston, E. S., Wakabayashi, J., Kwak, M. K. et al. Regulation of notch1 signaling by nrf2: implications for tissue regeneration. Sci. Signal. 3, ra52 (2010).

50. Paul, M. K., Bisht, B., Darmawan, D. O., Chiou, R., Ha, V. L., Wallace, W. D. et al. Dynamic changes in intracellular ROS levels regulate airway basal stem cell homeostasis through Nrf2-dependent Notch signaling. Cell Stem Cell 15, 199-214 (2014).

51. Solis, L. M., Behrens, C., Dong, W., Suraokar, M., Ozburn, N. C., Moran, C. A. et al. Nrf2 and Keap1 abnormalities in non-small cell lung carcinoma and association with clinicopathologic features. Clin. Cancer Res. 16, 3743-3753 (2010).
52. Mitsuishi, Y., Taguchi, K., Kawatani, Y., Shibata, T., Nukiwa, T., Aburatani, H. et al. Nrf2 redirects glucose and glutamine into anabolic pathways in metabolic reprogramming. Cancer Cell. 22, 66-79 (2012).

53. Hommura, F., Dosaka-Akita, H., Mishina, T., Nishi, M., Kojima, T., Hiroumi, H. et al. Prognostic significance of p27KIP1 protein and ki-67 growth fraction in non-small cell lung cancers. Clin. Cancer Res. 6, 4073-4081 (2000).

54. Warth, A., Cortis, J., Soltermann, A., Meister, M., Budczies, J., Stenzinger, A. et al. Tumour cell proliferation (Ki-67) in non-small cell lung cancer: a critical reappraisal of its prognostic role. Brit J. Cancer 111, 1222-1229 (2014).

55. Borggrefe, T. \& Liefke, R. Fine-tuning of the intracellular canonical Notch signaling pathway. Cell Cycle 11, 264-276 (2012).

56. Kauppinen, R. A., Sihra, T. S. \& Nicholls, D. G. Aminooxyacetic acid inhibits the malate-aspartate shuttle in isolated nerve terminals and prevents the mitochondria from utilizing glycolytic substrates. Biochim. Biophys. Acta 930, 173-178 (1987).

57. Guo, L., Zhang, T., Xiong, Y. \& Yang, Y. Roles of NOTCH1 as a therapeutic target and a biomarker for lung cancer: controversies and perspectives. Dis. Markers 2015, 520590 (2015).

58. Scagliotti, G. V., Parikh, P., von Pawel, J., Biesma, B., Vansteenkiste, J., Manegold, C. et al. Phase III study comparing cisplatin plus gemcitabine with cisplatin plus pemetrexed in chemotherapy-naive patients with advanced-stage non-small-cell lung cancer. J. Clin. Oncol. 26, 3543-3551 (2008).

59. Hayashi, H., Kurata, T. \& Nakagawa, K. Gemcitabine: efficacy in the treatment of advanced stage nonsquamous non-small cell lung cancer. Clin. Med. Insights Oncol. 5, 177-184 (2011).

60. McCluskey G., Bearne S. Gemcitabine is a competitive inhibitor of cytidine-5'triphosphate synthase (CTPS) that induces enzyme filament polymerization. Faseb J. 29, Suppl. 1 (2015).

61. Jin, M., Kawakami, K., Fukui, Y., Tsukioka, S., Oda, M., Watanabe, G. et al. Different histological types of non-small cell lung cancer have distinct folate and DNA methylation levels. Cancer Sci. 100, 2325-2330 (2009).

62. Jiang, L., Shestov, A. A., Swain, P., Yang, C., Parker, S. J., Wang, Q. A. et al. Reductive carboxylation supports redox homeostasis during anchorage-independent growth. Nature 532, 255-258 (2016).

63. Maddocks, O. D. K., Athineos, D., Cheung, E. C., Lee, P., Zhang, T., van den Broek, N. J. F. et al. Modulating the therapeutic response of tumours to dietary serine and glycine starvation. Nature 544, 372-376 (2017).

Open Access This article is licensed under a Creative Commons Attribution 4.0 International License, which permits use, sharing, adaptation, distribution and reproduction in any medium or format, as long as you give appropriate credit to the original author(s) and the source, provide a link to the Creative Commons license, and indicate if changes were made. The images or other third party material in this article are included in the article's Creative Commons license, unless indicated otherwise in a credit line to the material. If material is not included in the article's Creative Commons license and your intended use is not permitted by statutory regulation or exceeds the permitted use, you will need to obtain permission directly from the copyright holder. To view a copy of this license, visit http://creativecommons. org/licenses/by/4.0/.

(c) The Author(s) 2019 